UNIVERSIDADE DE SÃO PAULO

INSTITUTO DE PSICOLOGIA

Departamento de Psicologia Experimental

Paulo Roberto Abreu

UM MODELO EXPERIMENTAL DO TRANSTORNO OBSESSIVOCOMPULSIVO BASEADO NAS RELAÇÕES FUNCIONAIS ENTRE RESPOSTAS VERBAIS E NÃO VERBAIS

São Paulo

2013 


\title{
PAULO ROBERTO ABREU
}

\section{UM MODELO EXPERIMENTAL DO TRANSTORNO OBSESSIVO- COMPULSIVO BASEADO NAS RELAÇÕES FUNCIONAIS ENTRE RESPOSTAS VERBAIS E NÃO VERBAIS}

\author{
Tese apresentada ao Instituto de \\ Psicologia da Universidade de São \\ Paulo, como parte dos requisitos para \\ a obtenção do grau de Doutor em \\ Psicologia. \\ Área de Concentração: Psicologia \\ Experimental \\ Orientadora: Profa. Dra Maria Martha \\ Costa Hübner
}




\section{AUTORIZO A REPRODUÇÃO E DIVULGAÇÃO TOTAL E PARCIAL DESTE TRABALHO, POR QUALQUER MEIO CONVENCIONAL OU ELETRÔNICO, PARA FINS DE ESTUDO E PESQUISA, DESDE QUE CITADA A FONTE.}

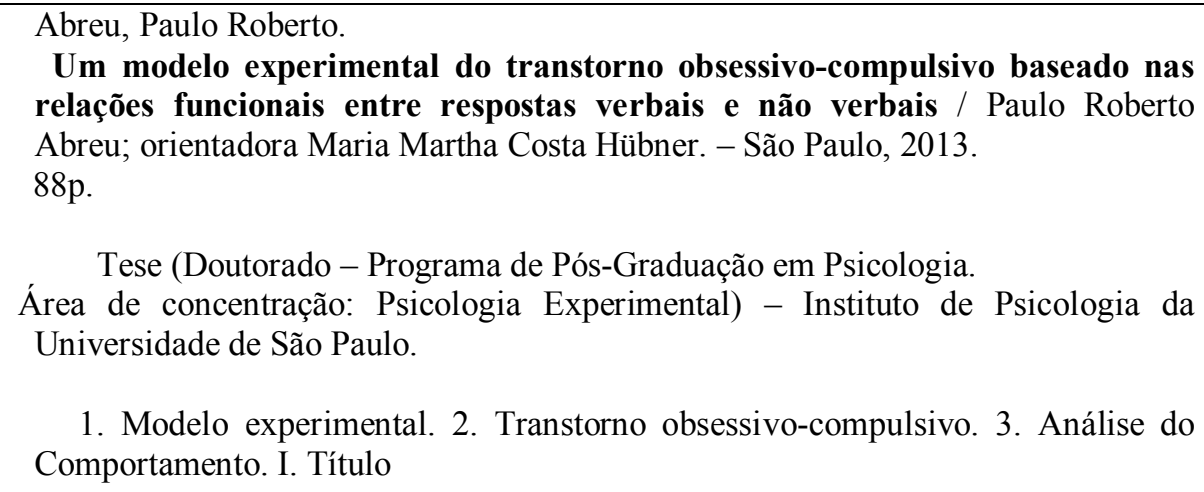

1. Modelo experimental. 2. Transtorno obsessivo-compulsivo. 3. Análise do Comportamento. I. Título 
FOLHA DE APROVAÇÃO

Paulo Roberto Abreu

Um modelo experimental do transtorno obsessivo-compulsivo baseado nas relações funcionais entre respostas verbais e não verbais.

Tese apresentada ao Instituto de Psicologia da Universidade de São Paulo para a obtenção de título de Doutor em Psicologia Experimental.

Área de concentração: Psicologia Experimental

Orientação: Profa Dra Maria Martha Costa Hübner

Aprovada em:

Banca Examinadora

Prof.

Instituição:

Assinatura:

Prof.

Instituição:

Assinatura:

Prof.

Instituição:

Assinatura:

Prof.

Instituição:

Assinatura:

Prof.

Instituição:

Assinatura: 


\section{AGRADECIMENTOS}

Ao longo desses anos todos acabei me apaixonando pela Análise Experimental do Comportamento Verbal, ainda que eu já tivesse alguma familiaridade com esse fenômeno dentro da área aplicada. Mas minha experiência com a aplicação não bastou. Meus interesses migraram de forma irreversível para a área de pesquisa básica. O que me seduziu mesmo foi o método experimental de produzir conhecimento em psicologia. Penso que fazer experimentações controladas é utilizar o método experimental para investigar quaisquer fenômenos comportamentais, independentemente de onde se julgue que as suas análises sejam importantes, seja no laboratório ou na aplicação. Aprendi isso tudo não em textos, mas dentro das salas e corredores do Instituto de Psicologia da USP.

E foi fundamental ter alguém que me conduziu nessa empreitada de apreço pelo conhecimento.

A diversidade de conhecimentos e interesses faz parte dos seus repertórios. Pesquisa básica, aplicada e conceitual. Foram muitos projetos em que você me convidou, acadêmicos ou até mesmo de divulgação cuidadosa de nossa ciência. O cansaço pela responsabilidade veio em alguns momentos, é verdade, mas nunca desprovido de enorme satisfação pelos pequenos progressos. Quando as coisas não davam tão certo, não faltaram ternura e compressão de sua parte. Em cada dia de minha vida tento exercitar isso. Aprendi contigo que mais importante do que saber verbalizar sobre reforçadores, é ser uma pessoa reforçadora. Obrigado pelo carinho e amizade Martha Hübner.

À família Abreu com grande amor - Teodoro Abreu, meu pai, minha fortaleza. Nunca mediu esforços para dar o melhor em educação. Amante dos fatos, muitas vezes 
mais do que se possa falar sobre eles. O melhor leitor de contingências que já conheci. Maria de Lourdes Abreu, minha mãe, minha alegria de viver - vê cores em coisas muito singelas - transforma em alegria as pequenas coisas do cotidiano. Mostra que não é necessário muito para um resultado grandioso. Marcelo Abreu, meu irmão, meu modelo de profissional. Assisti à graciosidade e firmeza na maneira com que lida com o trabalho. Você pode não ter se dado conta, mas bom humor e reinvenção foi o que aprendi. Alexsandra Abreu, meu primeiro e único contato com a psicologia. Eu não seria psicólogo se não tivesse sido por você, e essa missão vou carregar pelo resto de minha vida. Catiane Abreu e Adilsom Silva, meus cunhados queridos, amo muito vocês. Nicole Abreu e Bianca Abreu Silva, minhas sobrinhas lindas, brincar é a melhor coisa que vocês me lembram de fazer.

À família Silvério - Sérgio Silvério, preocupação extrema para que esse estudo de doutorado ocorresse. Lucas Silvério, você conseguiu transformar a preparação do restaurante experimental em uma atividade divertida. Vera, Bruno, Tatiana e Rodolfo sempre curiosos para saber do progresso de toda a pesquisa. Amo vocês! Muito obrigado.

Ao meu amigo Antônio Pinto. Obrigado por ter concedido o espaço do seu restaurante para que essa pesquisa fosse rodada. Sou muito grato à receptividade com que recebeu toda a equipe de pesquisa.

Sonia Meyer, ler o Comportamento Verbal sob a sua tutoria foi apaixonante. Mais do que isso. Aprender contigo sobre esse livro, aplicado na clínica comportamental, foi um privilégio. 
Miriam Mijares mostrou que o estudo primoroso dos modelos experimentais de psicopatologia e da farmacologia comportamental pode, certamente, ser uma das maiores contribuições para o entendimento contextual e tratamento das psicopatologias.

Roberto Banaco você continua sendo para mim um modelo de dedicação à interdisciplinaridade. Suas articulações do laboratório com a clínica comportamental encantam. Sua contribuição como modelo de terapeuta brasileiro foi definitiva na minha formação.

Denis Zamignani, o maior especialista comportamental em TOC que conheço. Se não fossem as suas primeiras experiências e textos abordando o assunto, então essa tese nunca teria sido escrita.

Agradeço imensamente a secretária do PSE Sonia Maria Caetano de Souza, que não mediu esforços para me acolher no programa e que sempre ajudou com os incontáveis trâmites acadêmicos. Sonia receba o meu mais sincero obrigado.

Ao longo de todo o percurso muitos amigos fizeram parte da jornada. Erickson Dambrós, meu irmão, continuamos a caminhada de longa data. Alexandre Werpachowski, sempre otimista. Marina, amiga guerreira, não cansa de sempre fazer mais, inspira. Obrigado pela parceria. 


\section{DEDICATÓRIA}

Juliana Helena

Quando eu tomo uma decisão boa, você é otimista. Quando eu tomo uma decisão ruim, você é otimista.

Amo muito essa sua teimosia. 
"The battle over Skinner's ideas is just beginning. It promises to be one of the most interesting contests of our generation.” (Gail Boyer, 1974, St. Louis Post-Dispatch) 


\section{RESUMO}

Abreu, P. R. (2013). Um modelo experimental do transtorno obsessivo-compulsivo baseado nas relações funcionais entre respostas verbais e não verbais. Tese de Doutorado, Instituto de Psicologia, Universidade de São Paulo, São Paulo.

Modelos experimentais do transtorno obsessivo compulsivo (TOC) com humanos mostram que uma forma de evocar comportamentos de checagem é apresentar instruções que especificam consequências aversivas para o comportamento inefetivo na execução de tarefas. Atualmente há na área somente um estudo experimental com delineamento de sujeito único. Os presentes dois experimentos com 16 participantes verbalmente habilidosos tiveram o objetivo de testar se instruções com especificação de consequência aversiva ou apetitiva poderiam ter o efeito de produzir respostas de checagem. Em um restaurante experimental, as instruções foram apresentadas durante uma tarefa de separação de sementes misturadas. No Experimento 1, cinco de oito participantes apresentaram maiores porcentagens de checagens sob especificação de consequência aversiva. No Experimento 2, sete de oito participantes apresentaram maiores porcentagens sob especificação de consequência apetitiva. Concluiu-se que determinadas instruções alteraram a função discriminativa e/ou motivadora dos estímulos envolvidos na tarefa experimental. Sugere-se que o presente delineamento pode permitir a formulação de análises funcionais do fenômeno comportamental normalmente envolvido em alguns casos de TOC.

Palavras-chave: comportamento governado por regras, modelo experimental, comportamento de checagem, estímulo especificador de contingência, comportamento de checagem, transtorno obsessivo-compulsivo. 


\begin{abstract}
Abreu, P. R. (2013). An experimental model of obsessive-compulsive disorder based on the functional relations between verbal and nonverbal responses. $\mathrm{PhD}$ dissertation, Instituto de Psicologia, Universidade de São Paulo, São Paulo.

Experimental models of obsessive compulsive disorder (OCD) with humans show that a way to evoke checking behaviors is to provide instructions that specify aversive consequences for behavior ineffective in performing tasks. Currently there is only one experimental study with a single subject design in this area. The present study presents two experiments with 16 verbally skilled participants tested whether instructions specifying the appetitive or aversive consequence could have the effect of producing checking behaviors. In an experimental restaurant, the instructions were presented during a task of separation of mixed seeds. In Experiment 1, five of eight participants showed higher percentages of checks under specification of aversive consequence. In Experiment 2, seven of eight participants had higher percentages under specification of appetitive consequence. It was concluded that certain instructions alter the discriminative and motivate function of the stimuli involved in experimental task. It is suggested that this design may allow the formulation of functional analysis of behavioral phenomenon normally involved in some cases of OCD.
\end{abstract}

Key words: rule-governed behavior, experimental model, checking behavior, contingencyspecifying stimulus, obsessive compulsive disorder. 


\section{LISTA DE FIGURAS}

FIGURA 1 - Porcentagens das respostas de checagem apresentadas pelos participantes P1, P3, P5 e P7 ao longo das fases experimentais ABA do Experimento 1.

FIGURA 2 - Porcentagens das respostas de checagem apresentadas pelos participantes P2, P4, P6 e P8 ao longo das fases experimentais BAB do Experimento 1.

FIGURA 3 - Porcentagens das respostas de checagem apresentadas pelos participantes P9, P11, P13 e P15 ao longo das fases experimentais ABA do Experimento 2.

FIGURA 4 - Porcentagens das respostas de checagem apresentadas pelos participantes $\mathrm{P} 10, \mathrm{P} 12$, P14 e P16 ao longo das fases experimentais BAB do Experimento 2. 


\section{LISTA DE TABELAS}

TABELA 1 - Apresentação da sequência de fases programadas ABA para cada

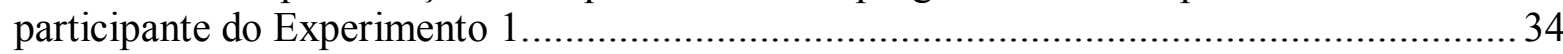

TABELA 2 - Apresentação da sequência de fases programadas BAB para cada

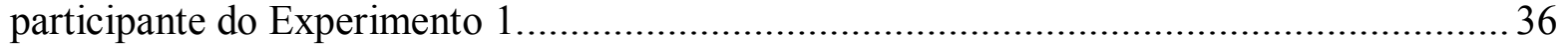

TABELA 3. Amplitude e porcentagem média de concordância entre observadores para cada participante do Experimento 1 ............................................... 42

TABELA 4 - Apresentação da sequência de fases programadas ABA para cada

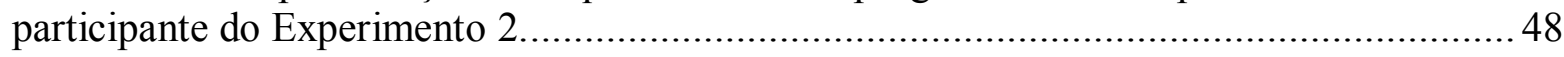

TABELA 5 - Apresentação da sequência de fases programadas BAB para cada participante do Experimento 2

TABELA 6. Amplitude e porcentagem média de concordância entre observadores para cada participante do Experimento $2 .$. 


\section{SUMÁRIO}

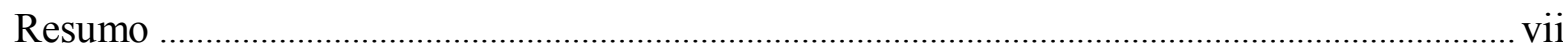

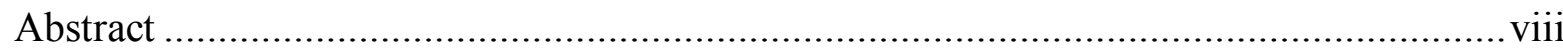

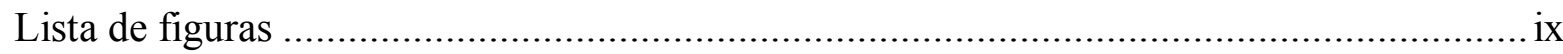

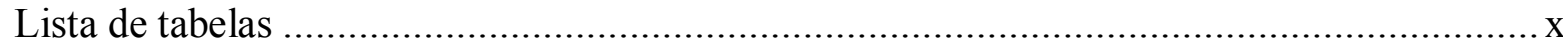

Comportamento verbal e comportamento governado por regras .................................... 4

Regras como estímulos alteradores de função ............................................... 8

Pesquisa experimental, modelos de psicopatologia e o comportamento

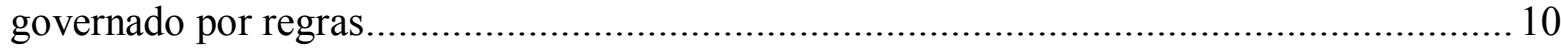

Estudos básicos de orientação cognitiva ........................................................... 12

Estudos básicos de orientação analítico-comportamental........................................ 20

Problemas de pesquisa e experimentos propostos ….......................................... 30

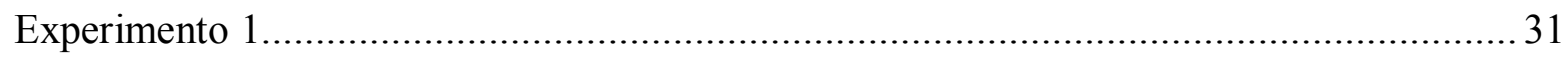

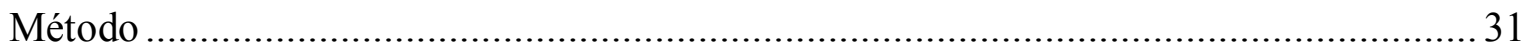

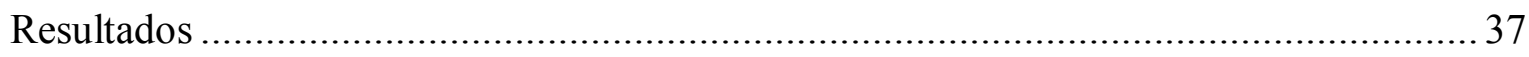

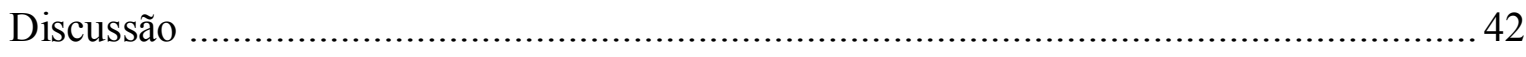

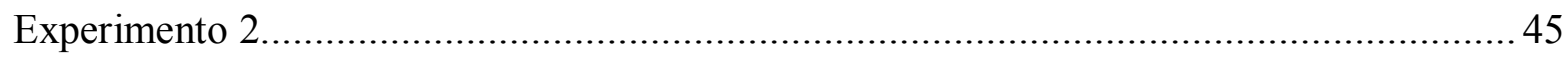

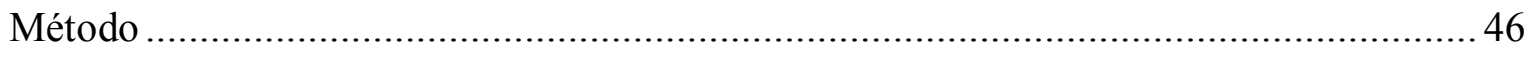

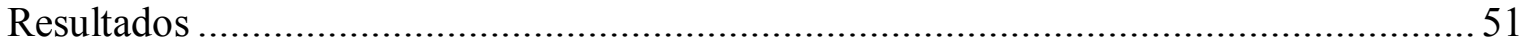

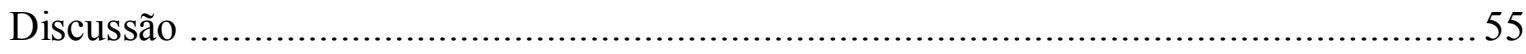

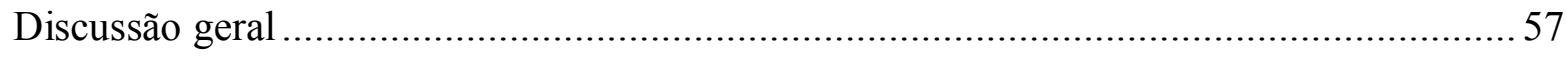

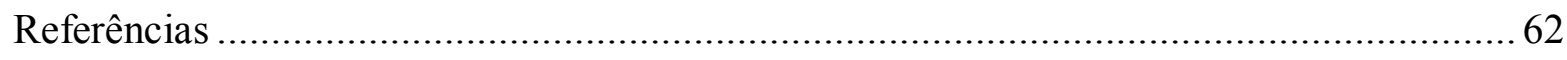

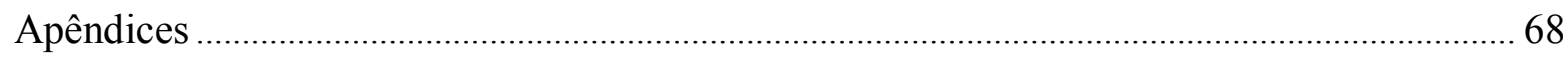


Para a Análise do Comportamento, o conjunto de fenômenos a que se convencionou chamar de psicopatologia é nada mais do que o aumento ou diminuição da frequência de certos comportamentos, em geral não desejados na cultura da pessoa, e que por isso mesmo podem trazer sofrimento significativo e prejuízo funcional (Ullmann \& Krasner, 1975). Dentro dessa concepção, os comportamentos "patológicos" não diferem dos de uma pessoa considerada normal, exceto pela diferença expressiva em sua frequência (Ferster, 1973). Assim também a ciência básica comportamental propõe que os modelos experimentais de psicopatologia não seriam de natureza distinta dos comportamentos assumidos como normais. Para que um modelo prove ser adequado nas investigações experimentais é necessário unicamente que ele englobe variáveis relevantes aos problemas de saúde mental (Skinner, 1972).

Comumente a Psicologia e a Análise Experimental do Comportamento empregam sujeitos animais nos modelos, vistos os problemas éticos, sociais, legais ou financeiros envolvidos em se utilizar humanos. Animais são utilizados em laboratório sob a suposição também de que ao pesquisador é possível modelar o comportamento patológico semelhante ao que ocorre em humanos (Mijares-Garcia, 2005). Dentre as psicopatologias já contempladas pelo desenvolvimento de modelos experimentais, destaca-se o transtorno obsessivo-compulsivo (TOC).

No TOC a polidipsia induzida por esquema tem sido o modelo mais amplamente reproduzido em laboratório (Silva, Guerra, \& Alves, 2005). Na polidipsia ocorre o beber 
excessivo em ratos privados de água, quando são submetidos a um esquema intermitente de liberação de alimento. O beber excessivo acontece logo após a ingestão do alimento e excede bastante a ingestão diária de sujeitos sob as mesmas condições de privação (Woods et al., 1993). Embora o modelo da polidipsia induzida por esquema tenha o potencial de explicar as compulsões em ratos, ainda assim continuaria existindo uma limitação relevante no seu alcance explicativo dos comportamentos observados em humanos com o diagnóstico - ela não explica os pensamentos repetidos ou "obsessões", um fenômeno verbal característico do TOC.

Em alguns casos de TOC, por exemplo, indivíduos mostram comportamentos de lavar repetidamente as mãos, que supostamente estariam sob o controle verbal de autoregras especificadoras de contaminação. Dentro desse contexto, o estudo básico do comportamento governado por regras pode ser importante para o aprimoramento dos modelos de TOC, pois algumas relações entre variáveis verbais e não verbais são de grande relevância na reprodução do fenômeno clínico em laboratório.

O presente estudo se propõe a apresentar um modelo experimental analíticocomportamental de TOC com humanos, baseado nas relações funcionais entre o comportamento verbal e o não-verbal. Pelo fato do fenômeno clínico envolver relações verbais, será feito inicialmente uma apresentação do referencial teórico adotado para a linguagem, sob a justificativa de que ele pode ser adequadamente aplicado na investigação do modelo. Para isso, serão apresentadas e discutidas as concepções behavioristas do (1) comportamento verbal e do (2) comportamento governado por regras. O estudo apresentará também uma (3) revisão da literatura, com estudos básicos cognitivos e comportamentais, que avaliam o efeito de diferentes instruções, com especificação de consequências 
aversivas, sobre as respostas de checagem. Nesse tópico, ainda, tentar-se-á desenvolver uma articulação teórica crítica entre essas duas correntes de pesquisa em psicologia. Em seguida serão apresentados o (4) problema de pesquisa e os (5) Experimentos 1 e 2, utilizando instruções com especificação de consequência aversiva e apetitiva, respectivamente. O trabalho será finalizado com uma (6) discussão geral sobre a relevância do método de pesquisa adotado na construção de um modelo experimental que explicite algumas variáveis de controle dos comportamentos "obsessivos" e "compulsivos". 


\section{COMPORTAMENTO VERBAL E COMPORTAMENTO GOVERNADO POR}

\section{REGRAS}

O comportamento operante age sobre o meio modificando-o, em uma ação mecânica direta. As consequências do comportamento alterarão por sua vez a probabilidade de emissão futura desse mesmo comportamento. Mas conforme sinaliza Skinner (1957/1992), muitas vezes o homem age indiretamente sobre seu ambiente, por intermédio de um outro homem. O agir de forma indireta aumenta a extensão com que um falante pode modificar seu ambiente, sobretudo quando o falante não tem repertório efetivo para a mudança desejada. Um pedido ou uma ordem de um falante controla o comportamento de outra pessoa caso essa tenha sido especialmente modelada em fazê-lo por uma comunidade verbal, ou seja, por um grupo de pessoas que falam entre si reforçando as verbalizações umas das outras (Baum, 2005). Dentro da comunidade verbal, a pessoa que medeia o reforçamento para o comportamento verbal do falante é chamada de ouvinte. A mediação do ouvinte relacionada aos eventos ambientais enfatiza o caráter mediacional que distingue o operante verbal dos outros comportamentos que mantêm contato direto com as consequências produzidas (Vargas,1998). O comportamento verbal é, portanto, definido como sendo o comportamento cujas consequências são mediadas por uma audiência que participa da mesma comunidade verbal que o falante (Skinner, 1957/1992).

Skinner (1957/1992) ilustra a mediação social do reforçamento dizendo que

“Um homem sedento, por exemplo, em vez de dirigir-se a uma fonte, pode simplesmente pedir um copo de água, isto é, pode produzir um comportamento 
constituído por certo padrão sonoro, o qual por sua vez induz alguém a lhe dar um copo de água. (...) A consequência última, o recebimento de água, não mantém qualquer relação geométrica ou mecânica com a forma do comportamento de pedir água.” (p. 1)

Em uma análise funcional do comportamento do falante como a descrita pelo autor, inicialmente é feita uma especificação do operante verbal de interesse para, em seguida, explicitar quais são as condições ambientais relevantes das quais ouvinte e falante participam. As descrições interligadas do comportamento do ouvinte e do falante descrevem uma explicação do episódio verbal total (Skinner, 1957/1992). Nesse sentido, o comportamento verbal opera como um sistema de relações contingentes interativas de ações mediadas (Vargas, 1998).

No âmbito do estudo do comportamento verbal, deu-se uma atenção especial ao aprendizado por regras, pois o comportamento por elas especificado pode ser aprendido mais rapidamente, proporcionando com isso algumas vantagens adaptativas, dentre elas a preservação dos indivíduos de nossa espécie em muitas situações de perigo (Skinner, 1974/1976). Assim, as pessoas de uma determinada comunidade ensinam a seus membros habilidades importantes, sem que esses necessitem aprender unicamente por meio das contingências especificadas pelas regras (Skinner, 1988).

Para Skinner (1969), regras são estímulos verbais especificadores de contingências que exercem função discriminativa para um ouvinte. Uma regra na função de antecedente verbal pode especificar o desempenho requerido do ouvinte sem fazer qualquer alusão às consequências de seu não seguimento (Catania, 2003; Catania, Matthews, \& Shimoff, 
1982). Nesses moldes, uma regra pode ser observada em formulações que especificam somente o comportamento a ser seguido, quando um falante diz "pare", "não faça assim" ou "saia". De outro modo, a regra pode especificar toda a contingência com sua consequência, a exemplo de alguém a quem é dito o que acontecerá se não disser ou fizer algo (Catania, 2003; Catania et al., 1982). As pessoas frequentemente optam por especificar as contingências que estão operando em determinado ambiente, sobretudo quando solicitam do outro comportamentos considerados apropriados ao contexto social. Dessa forma, por exemplo, as agências controladoras frequentemente promovem o seguimento de regras por meio da especificação de consequências aversivas a curto, médio e longo prazo para o não seguimento (Sidman, 1989/2001; Skinner 1953/1968). A ameaça do inferno para os comportamentos pecaminosos ou as placas de trânsito que trazem avisos de multa para as infrações, normalmente observados em igrejas e governos, respectivamente, são exemplo de regras que podem especificar os três termos da tríplice contingência ${ }^{1}$.

Orientações, leis, conselhos, avisos e ordens são tidos como bons exemplos de controle por regras. Dentro desse contexto, um controle instrucional ocorre sob a instrução verbal do falante que especifica um modo especial de agir do ouvinte. De fato, a função mais ampla do comportamento verbal é a possibilidade do falante dizer ao ouvinte o que fazer ou o que dizer.

Regras como instruções evocam comportamentos do ouvinte porque o seu comportamento de seguir regras foi substancialmente reforçado no passado por uma

\footnotetext{
${ }^{1}$ Segundo Matos (2001), o termo regra frequentemente tem sido usado para descrever uma variedade de circunstâncias antecedentes e de respostas, embora estudos recentes tragam a expressão instruções para especificar as circunstâncias em que acontece a ação. Similarmente à abordagem da autora, na presente tese os dois termos serão utilizados indistintamente.
} 
comunidade verbal. Por esse motivo, Catania (2003) define o comportamento governado por regras como sendo um operante de ordem superior, cujos membros seriam casos particulares do seguimento de regras específicas. No operante de ordem superior as consequências mediadas socialmente são as variáveis responsáveis pela instalação e manutenção do comportamento de seguir regras. ${ }^{2}$ Assim, por exemplo, as pessoas em culturas judaico-cristãs historicamente aprendem a dar comida, bens ou dinheiro para pedintes em necessidade, por meio do reforço mediado pelos membros da comunidade. Por outro lado, as consequências atuais mediadas socialmente, produzidas pelos casos particulares, podem alterar a probabilidade futura de certos comportamentos de seguir regras (Perone, Galizio, \& Baron, 1988). Dessa forma, um ouvinte que tenha aprendido a dar dinheiro aos necessitados poderá vir a deixar de fazê-lo, ainda que abra concessões quanto à comida. Isso ocorre em circunstâncias em que a comunidade verbal passa a punir o comportamento de dar dinheiro sob o controle de regras que alertam para os problemas gerados pela prática de dar esmolas.

\footnotetext{
${ }^{2}$ No episódio verbal, tanto o comportamento do falante é reforçado pela mediação social do ouvinte, como o comportamento de seguir a regra do ouvinte é reforçado pela mediação social do falante (Greer, 2009).
} 


\section{Regras como Estímulos Alteradores de Função}

Desde a publicação de o Comportamento Verbal (Skinner, 1957/1992), poucos analistas do comportamento abordaram o efeito alterador de função do estímulo verbal (e.g. Alessi, 1992; Hayes \& Hayes, 1989; Hayes, Barnes-Holmes, \& Roche, 2001; Palmer, 1998, 2007; Schlinger \& Blakely, 1987, 1994). Para Schlinger e Blakely (1987) as regras são estímulos verbais alteradores de função por modificarem a função de estímulos não verbais por elas especificados, produzindo com isso mudanças no comportamento evocado. Essa interpretação aproximaria os efeitos comportamentais do estímulo verbal dos efeitos alteradores de função encontrados no condicionamento operante e respondente (Michael, 1983). Os autores utilizaram o termo Estímulo Especificador da Contingência (CSS) de Skinner (1969), e também operação verbal alteradora de função (Schlinger , 2008a; 2008b), para se referir à regra como sendo um estímulo que teria a função de modificar a função dos estímulos ambientais arbitrariamente relacionados. Dessa forma, um CSS produz mudanças nos estímulos especificados da contingência, sendo estes estímulos discriminativos, eliciadores, operações estabelecedoras (OEs) ou estímulos consequentes (Schlinger, 1993). Mas segundo a conceituação de Schlinger e Blakely (1987), o efeito evocativo residiria no estímulo discriminativo (SD) especificado na regra, não na regra em si, conforme descreve a conceituação skinneriana clássica (cf., Schlinger, 1990, 1993). Dessa forma, em uma instrução como "quando você vir o chefe lhe dê os parabéns", a regra seria um CSS e, o estímulo chefe, o SD. A emissão do CSS altera a função do estímulo chefe para uma função discriminativa que irá controlar a resposta do ouvinte de dar os parabéns. Sendo assim, a regra não poderá exercer diretamente a função de SD, pois o 
ouvinte só parabenizará o chefe quando este estiver na sua presença. Em o Comportamento Verbal, Skinner (1957/1992) dá um exemplo similar, ilustrando o efeito alterador de função exercido pelo estímulo verbal. Diz o autor que:

“O estímulo verbal ‘Quando eu disser três, vá!’ pode não ter efeito imediato classificável como uma resposta, mas ele muda o comportamento subsequente do ouvinte com relação ao estímulo 'Três'. Nós estamos... preocupados... com o comportamento operante de "ir" evocado pelo estímulo discriminativo 'três'." (pp. 358-359).

Anteriormente a essa instrução, o comportamento verbal "três" não evocaria o comportamento de sair em disparada. Mas a resposta verbal "Quando eu disser três" momentaneamente aumenta a função evocativa do estímulo "três, vá". Assim, é possível afirmar que o estímulo verbal "três" teve sua função alterada para uma função discriminativa para a resposta de "ir".

Em uma outra interpretação da função de estímulo, regras poderiam ser entendidas como sendo unicamente operações estabelecedoras, haja vistas as suas propriedades de aumentar a efetividade de algum objeto/evento consequente como reforçador e de evocar qualquer comportamento que tenha produzido dado reforçador no passado (Malott, 1988; Malott, 1989). Contingências de controle aversivo normalmente são bons exemplos de OE por aumentar o valor da suspensão da estimulação aversiva e por evocarem os comportamentos de fuga ou esquiva (Michael, 1982, 1993, 2000). 
Uma instrução que especifique a resposta a ser seguida pelo ouvinte, sinalizando consequências aversivas para o não seguimento, poderia preencher esses critérios. Assim, uma instrução como a "se você não tirar as roupas do varal elas vão molhar na chuva", estabeleceria como condições aversivas a resposta concorrente ao seguimento da regra e sua consequência (e.g., ficar jogando vídeo game). Já o seguimento da regra suspenderia ou reduziria a aversividade. Um possível seguimento de regra, nesse contexto, seria o ouvinte retirar a roupa do varal em um comportamento de esquiva. Determinada regra evocaria o seu seguimento atenuando com isso a aversividade para o não seguimento (Braam \& Malott, 1990; Malott, 1988; Malott, 1989).

\section{PESQUISA EXPERIMENTAL, MODELOS DE PSICOPATOLOGIA E O COMPORTAMENTO GOVERNADO POR REGRAS}

As explicações cognitivas para o TOC enfatizam o papel singular da variável verbal quando focam os pensamentos do obsessivo-compulsivo no desenvolvimento, manutenção e modificação das checagens (Rachman, 2002). Pela contiguidade consistente entre pensamentos e rituais, não seria de se estranhar que a ciência psicológica tenha perseguido uma determinação cognitiva para os comportamentos compulsivos. O modelo enfatiza a relação causal R-R (resposta encoberta-resposta aberta) como sendo uma explicação causal útil no entendimento do fenômeno. Esse tipo de interpretação rapidamente alcançou um alto status conceitual dentro da pesquisa básica e aplicada, e hoje constitui o mainstream interpretativo de escolha naquela abordagem. 
Um subtipo de indivíduos com o diagnóstico de TOC, chamados de "checadores" (Franklin, \& Foa, 2008), parece também apresentar uma relação R-R entre respostas abertas e encobertas. Nela, o primeiro elo da díade seria constituído pelas auto-regras contidas nas "respostas obsessivas" e o segundo elo pelas respostas verbalmente governadas, tradicionalmente concebido na literatura como sendo constitutivo das "compulsões" (Abreu \& Prada, 2004, 2005; Zamignani, 2001; Zamignani, \& Banaco, 2005). De acordo com essa conceituação clássica, os indivíduos poderiam apresentar compulsões de checagem sob o controle de obsessões, relacionadas às regras que especificam responsabilidade pessoal, como em uma auto-instrução em que um indivíduo diz a si mesmo que "sua família correrá perigo se não conferir a válvula do gás".

Posturas interpretativas cognitivas compreendem que o comportamento é controlado por processos simbólicos localizados na consciência ou mente. Matos (2001) afirma que no behaviorismo radical tanto a linguagem, os processos simbólicos e as regras são comportamento verbal, gerados no ambiente social. O comportamento governado por regras seria, portanto, sub-produto da interação social e não causa de outros comportamentos (Matos, 2001). De acordo com essa concepção, na análise de uma relação $\mathrm{R}-\mathrm{R}$ entre auto-regras e respostas abertas, precisaríamos antes investigar quais são as variáveis atuais (e históricas) antecedentes e consequentes que estariam controlando determinada relação. No TOC, por exemplo, a checagem controlada por regras ocorreria por meio de respostas repetidas, cuja função seria esquivar ou escapar de algum evento aversivo externo ao organismo, sendo este evento, em geral, consequente a uma resposta inefetiva em produzir mudanças específicas no ambiente. Nesse sentido, para o indivíduo com TOC, o contato com o evento aversivo é consequência de uma resposta de checagem 
inefetiva, e para que isso não ocorra, novas respostas de checagem deverão, portanto, ser emitidas.

A concepção analítico-comportamental se mostra bastante díspar dos entendimentos trazidos na psicologia tradicionalmente orientada para explicações internalistas para os problemas de comportamento. Por esse motivo, transpor explicações mentalistas para as psicopatologias tem ainda se tornado um grande desafio.

\section{Estudos básicos de orientação cognitiva}

Estudos experimentais dentro da tradição cognitiva mostram que uma forma efetiva de levar alguém a apresentar comportamentos de checagem é apresentar instruções especificadoras de consequências negativas que atribuem excessiva responsabilidade na execução de uma tarefa (Arntz, Voncken, \& Goosen, 2007; Bouchard, Rhéaume, \& Ladouceur, 1999; Mancini, D’Olimpio, \& Cieri, 2004; Ladouceur et al., 1995; Ladouceur, Rhéaume, \& Aublet, 1997; Lopatka \& Rachman, 1995). A responsabilidade é definida dentro da hipótese cognitiva como uma crença que alguém traz de possuir um poder de provocar ou prevenir consequências negativas cruciais (Salkovskis, Richards, \& Forrester, 1995). Determinadas consequências podem ser concretas ou morais (Salkovskis et al., 1995). Dito de outra forma, guardam relação direta com as contingências ou apenas são especificadas pelas regras sociais. O conceito enfatiza duas "distorções cognitivas" relacionadas: a influência pessoal e as consequências negativas. Uma consequência negativa seria um evento cuja probabilidade de ocorrência não dependeria diretamente do comportamento do indivíduo. Assim por exemplo, para um participante de pesquisa, uma 
consequência negativa pode vir a ocorrer como consequência do desempenho de mais de uma pessoa. Por seu turno, a influência pessoal seria a "percepção" do indivíduo sobre o seu papel causal na produção do evento. Nesse sentido, o participante teria a consciência verbal de que o evento negativo foi diretamente produzido pelo seu desempenho inefetivo.

Ladouceur e colaboradores (1995) publicaram dois experimentos examinando diferentes níveis de responsabilidade e sua influência em comportamentos de checagem, verificando algumas semelhanças com os comportamentos compulsivos observados no transtorno obsessivo-compulsivo. Com resultados relevantes, o Experimento 2 adotou como tarefa uma classificação em contexto farmacológico. No experimento, quarenta participantes adultos foram orientados a separar pílulas coloridas misturadas. Foram confeccionadas duzentas cápsulas farmacêuticas de açúcar, com dez combinações de cores, sendo vinte cápsulas de cada cor. As cápsulas foram colocadas misturadas em uma bacia e quinze garrafas vazias semitransparentes foram dispostas para acondicionar as pílulas de acordo com a cor designada

Os participantes foram distribuídos randomicamente entre um grupo de alta responsabilidade (HR) e outro de baixa responsabilidade (LR). Ambos os grupos foram instruídos a pegar uma cápsula por vez, sem olhar para a bacia, colocando nas garrafas de acordo com a cor designada. Os participantes teriam que classificar as pílulas adequadamente o mais rápido possível. Poderiam conferir as garrafas e corrigir os erros o tanto quanto achassem necessário, em casos que hesitassem ou apresentassem alguma dúvida durante na tarefa. As seguintes instruções foram apresentadas para o grupo HR e LR, respectivamente: 
Indução de responsabilidade (HR): $\mathrm{O}$ experimentador falava para os participantes que o grupo de pesquisa era especializado na percepção de cores e que havia sido recentemente contratado por uma indústria farmacêutica para trabalhar em um estudo relacionado à exportação de uma nova droga, criada para tratar um vírus que estava devastando o sudeste da Ásia. Aos participantes foi dito ainda que a região era muito pobre e que por isso sua população não tinha muito estudo. Por esse motivo houve a necessidade de que se desenvolvesse um sistema de cores que tornasse a distribuição das novas pílulas segura para os habitantes. Foi enfatizado que o papel dos participantes seria crucial para o sucesso do projeto e que seus resultados seriam decisivos, já que o estudo estava em sua fase final. Adicionou-se também a informação de que poderiam prevenir sérias consequências, pois os resultados do trabalho influenciariam diretamente a manufatura das drogas.

Redução de responsabilidade (LR): Era dito aos participantes que o experimentador estaria interessado apenas na percepção das cores e que o experimento era somente um treino a ser realizado antes de o estudo começar. Acrescentou-se que os resultados individuais não seriam analisados.

Para verificar os efeitos da manipulação, quatro questões foram feitas. As questões eram relativas à percepção da probabilidade e severidade das consequências negativas, além da influência do participante sobre as consequências e sua percepção de responsabilidade. Utilizaram-se ainda como variáveis de controle o Inventário Beck de Depressão (BDI; Beck, Rush. Shaw, \& Emory, 1979), o Inventário Beck de Ansiedade (BAI; Beck, Epstein, Brown, \& Steer, 1988) e o Inventário Pádua (PI; Sanavio, 1988). O 
inventário Pádua permite acessar diferentes aspectos do TOC como os impulsos, lavagens, checagens, ruminações e precisão.

As variáveis dependentes foram medidas por observação direta. Quatro topografias de resposta foram então categorizadas:

(1) Hesitações, definidas como a observação atenta da garrafa por $2 \mathrm{~s}$ ou mais, ou como o movimento das mãos do participante entre duas pílulas diferentes por pelo menos $2 \mathrm{~s}$;

(2) Conferências e modificações durante a tarefa, definidas como a interrupção da separação em uma determinada garrafa, por aproximadamente 1s, com o despejamento para observação do seu interior. O esvaziamento do conteúdo da garrafa na palma da mão também foi contabilizado. As modificações referiam-se a qualquer mudança feita durante a tarefa em que se tenha adicionado ou subtraído uma ou mais cápsulas de alguma garrafa;

(3) O número de erros ocorridos durante a tarefa;

(4) O tempo demandado na classificação.

As variáveis subjetivas foram avaliadas com um questionário incluindo (1) dúvidas e urgência em conferir; (2) desconforto experienciado durante a tarefa e (3) os números de erros "subjetivos" feitos ao longo da tarefa.

Ao final da sessão o experimentador revelava o experimento, explicando ao participante os objetivos e procedência da pesquisa com a solicitação de assinatura em termo de consentimento para o uso dos dados.

Os resultados mostraram que os participantes do grupo HR hesitaram e conferiram mais do que o grupo LR. Também apresentaram maior preocupação e ansiedade com os erros durante a tarefa. De acordo com a definição de responsabilidade de Salkoviskis e colaboradores (1995), tanto a influência individual como também os aspectos cruciais das 
consequências negativas estariam envolvidos na percepção de responsabilidade. Concluíram Ladouceur e colaboradores (1995) que os dados são interessantes por darem suporte empírico para a relação direta entre a percepção de responsabilidade e os comportamentos de checagem. Contudo, para os autores, esse estudo não pôde avaliar o efeito de ambas as variáveis em separado no controle dos comportamentos de checagem.

Em um estudo posterior Ladouceur e colaboradores (1997) testaram o efeito da influência pessoal e o efeito das consequências negativas em situações de tomada de decisão em adultos. O objetivo do delineamento seria isolar a variável crítica na determinação das checagens. Setenta e sete participantes foram distribuídos em quatro amostras instruídas a separar as cápsulas. Foram empregadas duzentas pílulas de diferentes cores (onze tipos, vinte pílulas de cada) e quinze garrafas semitransparentes. As variáveis dependentes desse estudo relacionadas aos comportamentos de checagem foram iguais às variáveis do primeiro estudo (Ladouceur et al., 1995).

As seguintes instruções foram então apresentadas às quatro amostras, respectivamente:

Condição combinada: Foi dada a mesma instrução do estudo de Ladouceur e colaboradores (1995) referente à instrução de indução de responsabilidade somada às consequências negativas

Condição de influência: Com o objetivo de aumentar a influência pessoal, foi adicionada, às instruções da condição combinada, a informação de que os participantes eram parte de uma pequena amostra de três pessoas e que devido a esse fato, seus resultados teriam uma influência direta nas conclusões do estudo. 
Condição de consequências negativas: As instruções gerais da condição combinada foram apresentadas, exceto que, com o objetivo de reduzir a influência pessoal, foi dito aos participantes que eles compunham uma equipe de dois mil participantes que levantariam dados para as conclusões do estudo.

Condição de controle: Apenas foi esclarecido que a fase era ainda uma situação de treino, portanto sem nenhuma consequência, já que os resultados não seriam analisados.

Três questões foram feitas para a conferência do efeito das manipulações experimentais. As questões eram relativas à percepção da probabilidade e severidade das consequências negativas, além da influência do participante sobre as consequências e a sua percepção de responsabilidade.

Ao final da sessão o experimentador revelava os objetivos reais do experimento, solicitando a assinatura do termo de consentimento, para o uso dos dados.

Os resultados mostraram, para os autores, que a denominada influência pessoal é o melhor preditor da percepção da responsabilidade. O aumento do potencial das consequências negativas foi suficiente para iniciar algumas topografias relacionadas a hesitações nos participantes, mas a combinação da influência e das consequências negativas foi necessária para produzir comportamentos de checagem. Ao discutirem os resultados, Ladouceur e colaboradores (1997) concluíram que "ainda que a probabilidade e severidade da consequência negativa estejam relacionadas à responsabilidade, seus efeitos foram menos acentuados" (p. 426).

$\mathrm{Na}$ trajetória das pesquisas cognitivas, os experimentos iniciais sobre o comportamento de checagem, empregando participantes não clínicos, deram margem a um outro questionamento empírico - se indivíduos com o diagnóstico de TOC iriam se engajar 
em checagens, mais do que as outras pessoas, quando colocados em situações que lhes fosse exigida responsabilidade pessoal. Para testar essa hipótese, Arntz e colaboradores (2007) estudaram vinte e sete participantes com TOC como primeiro diagnóstico, trinta e sete participantes com outro transtorno de ansiedade como primeiro diagnóstico e sem TOC como segundo e, ainda, vinte e oito participantes sem nenhum diagnóstico do Eixo-1 do DSM-VI-TR (American Psychiatric Association, 2003).

Similarmente ao estudo de Ladouceur e colaboradores (1995), os participantes foram instruídos a separar duzentas cápsulas, de onze cores diferentes, acondicionadas em um pote. Atrás desse pote principal, quinze potes menores foram dispostos em linha para separação.

O delineamento do estudo foi um fatorial $2 \times 3$, com duas condições experimentais denominadas alta responsabilidade (HiRes) e baixa responsabilidade (LoRes) - e três grupos de participantes, a saber, pacientes com diagnóstico de TOC (OCD patients), pacientes com diagnóstico de ansiedade (Anx patients) e não pacientes do grupo controle (NonPt controls).

$\mathrm{Na}$ instrução de baixa responsabilidade foi dada a mesma instrução empregada no estudo de Ladouceur e colaboradores (1995). A instrução de alta responsabilidade também foi similar ao do estudo anterior, mas adicionou-se a informação de que "um estudo prévio empregou participantes que não se sentiram responsáveis o suficiente, fazendo por isso um péssimo trabalho de classificação" (Arntz et al., 2007, p. 427). O objetivo desse acréscimo foi aumentar o controle da instrução sobre os participantes já que em um estudo piloto a instrução descrita em Ladouceur e colaboradores (1995) não exerceu seu efeito. 
No estudo de Arntz e colaboradores (2007), algumas respostas encobertas foram aferidas por meio da escala análoga visual (VASs). Essa escala mediu as experiências subjetivas relatadas com relação ao comportamento de checagem. A variável dependente foi também o comportamento de checagem, definido de acordo com as mesmas topografias operacionalizadas por Ladouceur e colaboradores (1995). Foi também adotado o inventário Pádua para mensurar diferentes aspectos do TOC.

Nos resultados, a análise do principal componente na escala $V A S$ revelou, segundo os autores (Arntz et al., 2007), três fatores subjetivos relevantes: (1) perigo (2) responsabilidade e (3) desconforto e experiências subjetivas de TOC. De especial relevância, nas experiências subjetivas de TOC o "grupo TOC HiRes" diferiu significativamente dos outros grupos. Somado a isso, os participantes do "grupo TOC HiRes" checaram com maior frequência, diferindo também significativamente dos outros grupos. Já o tempo dispendido na finalização da tarefa foi significativo somente entre pacientes e não pacientes.

Os autores concluíram que situações de alta responsabilidade induzem checagem em maior frequência e com maiores escores de experiências subjetivas de TOC (Arntz et al., 2007). Os resultados confirmaram a hipótese de que somente o "grupo TOC HiRes" relataria experiencias subjetivas de TOC alta. Mais importante, somente o "grupo TOC HiRes", e não o "grupo TOC LoRes", apresentou novos comportamentos de checagem. 


\section{Estudos básicos de orientação analítico-comportamental}

Para Willner (1991), o desenvolvimento de um modelo experimental de psicopatologia deverá ser pautado em três critérios para ser considerado válido: (1) o critério preditivo, (2) o critério nominal e o (3) critério de validade de construto.

O primeiro critério (preditivo), afirma que o desempenho do modelo deve predizer o desempenho na situação modelada. Nesse sentido, o modelo de Ladouceur e colaboradores atendeu ao critério. Os participantes submetidos às instruções com especificação de consequências aversivas aumentaram a frequência das respostas de checagem em contextos análogos (Arntz, et al., 2007; Bouchard, et al., 1999; Mancini, et al., 2004; Ladouceur et al., 1995; Ladouceur, et al., 1997; Lopatka \& Rachman, 1995).

O segundo critério de Willner (nominal) especifica a necessidade da similaridade de fenômenos entre o modelo e a condição modelada. O método desenvolvido para o estudo das respostas de checagem em laboratório reproduziu alguns padrões comportamentais observados nos indivíduos diagnosticados com um subtipo clínico do TOC (Ladouceur et al, 1997).

Finalmente, o terceiro critério (de validade de construto), estabelece que o modelo precisa estar embasado em uma teoria robusta sobre o comportamento a que se deseja estudar. Mas o modelo de TOC desenvolvido por Ladouceur e colaboradores (1997), embora atinja os dois primeiros critérios, não está sobremaneira embasado em uma teoria robusta, pois conforme sinaliza De Rose (1999), apesar de assumirem entidades iniciadoras do comportamento, portanto internas ao organismo, as teorias cognitivas só podem inferir essas entidades a partir de eventos comportamentais. 
A explicação cognitiva para os dados levantados no estudo de Ladouceur e colaboradores (1997) enfatiza que os comportamentos de checagem ocorrem quando os indivíduos trazem "crenças" relacionadas à alta responsabilidade em prevenir danos. Contudo os experimentos cognitivos aqui descritos aferiram apenas o efeito produzido pela apresentação de instruções com especificação de consequências aversivas, que, na concepção cognitiva, se referem à especificação de "responsabilidade pessoal aumentada" e “consequências negativas".

A Análise Experimental do Comportamento traz dados que poderiam favorecer uma interpretação das contingências envolvidas no governo verbal observado nos estudos cognitivos sobre comportamentos de checagem (Arntz et al., 2007; Ladouceur et al., 1995; Ladouceur et al., 1997). Em especial, o experimento conduzido por Braam e Malott (1990), investigou se o controle por regras é alterado também por meio da manipulação da formulação verbal.

No estudo de Braam e Malott (1990), quatro regras similares foram apresentadas para oito crianças pré-escolares de aproximadamente quatro anos de idade. As contingências descritas pelas regras variaram na especificação dos prazos e no atraso para a apresentação dos reforços. As respostas medidas foram o pegar os brinquedos solicitados ou a montagem de um quebra-cabeça. Para tanto, quatro condições foram programadas em que cada tipo de regra era apresentada. As sessões de coleta aconteciam duas vezes por semana, ao longo de trinta minutos. As condições experimentais foram dispostas da seguinte forma:

Condição de Pedidos: Na primeira condição em que eram apresentados os pedidos, o experimentador descrevia regras incompletas. O experimentador solicitava que os 
participantes pegassem os brinquedos, mas não especificava prazos ou o reforçamento na instrução dada. Assim era dito à criança "Nicole, você poderia pegar os brinquedos?" (Braam \& Malott, 1990, p. 70). Após 5 minutos uma nova solicitação era feita independentemente de a criança ter atendido a instrução.

Condição de Prazos: Nessa condição o experimentador descrevia regras com prazos e reforçadores imediatos para que a criança pegasse os brinquedos (eg., "Se você pegar o brinquedo agora, poderá brincar na Caixa Mágica ${ }^{3}$ depois.”). Randomicamente era apresentada uma condição denominada $\mathrm{S}^{\mathbf{\Lambda}}$, em que as regras descreviam apenas a resposta de pegar os brinquedos e o prazo, mas não o reforçamento para o cumprimento da tarefa (eg., "Se você pegar o brinquedo agora, não poderá brincar na Caixa Mágica depois."). Esse esquema foi adotado para verificar se a resposta das crianças estaria sob o controle da especificação das contingências pelas regras ou sob o controle generalizado das demandas características do ambiente escolar infantil (e.g., na hipótese de que a resposta estivesse sob o controle das demandas, as crianças pegariam o brinquedo mesmo na condição $S^{\mathbf{\Lambda}}$ ). Diferentes crianças estavam em diferentes condições no mesmo dia (eg., reforçamento versus não reforçamento). Contudo, somente uma condição estava vigorando para uma dada criança, consistindo de uma ou duas tentativas.

Condição sem prazos e com reforços atrasados: Nessa condição o experimentador apresentava uma regra que descrevia o reforçador atrasado de uma semana e nenhum prazo para o cumprimento da tarefa. (e.g., "Aqui está uma quebra cabeças que você pode montar. Eu não me importo se você montar ou não. Essa é a regra: não importa se você montar bem

\footnotetext{
${ }^{3}$ A Caixa Mágica continha uma variedade de reforçadores, como pequenos dinossauros, carros, adesivos, estampas, etc)
} 
o quebra-cabeça, você só poderá brincar na Caixa Mágica uma semana depois que terminar de montá-lo.’).

Condição com prazos e com reforços atrasados: Durante essa condição o experimentador apresentava regras com especificação de prazos e com a especificação do reforçamento atrasado de uma semana. (e.g., "Aqui está um quebra-cabeça que você pode montar. Eu não me importo se você montar ou não. Essa é a regra: se você montar o quebra-cabeça agora, você só poderá brincar na Caixa Mágica uma semana depois que terminar de montá-lo.”)

Os resultados do estudo mostraram que na condição de pedidos as regras que descreviam somente o comportamento esperado, portanto sem a especificação do prazo e de reforçamento, não exerceram controle sobre o comportamento das crianças. Somente $42 \%$ dessas regras foram seguidas pelo grupo. Quando as regras apresentavam prazos e reforço imediato, 97\% das regras apresentadas foram seguidas pelo grupo. Nas tentativas em $\mathrm{S}^{\boldsymbol{\Lambda}}$ o grupo respondeu a apenas $31 \%$ das regras. Esse dado evidencia que as respostas do grupo ficaram, sobretudo, sob o controle da regra com especificação de prazo e reforçador imediato, e não das características do ambiente ou do experimentador. Na condição sem prazos e reforço atrasado as regras descritas estabeleceram um fraco controle operante. Somente $28 \%$ das tarefas solicitadas foram atendidas pelo grupo. Por fim, na condição com prazos e reforço atrasado, observou-se que $74 \%$ das solicitações foram atendidas pelo grupo. Esse resultado mostra que a especificação de prazo para a finalização da tarefa pode aumentar o controle das instruções sobre as crianças, mesmo nos casos em que a consequência anunciada for atrasada. 
O fraco controle das regras que estipulavam somente o comportamento (sem o anúncio de prazos e consequências) foi evidenciado com os dados de Braam e Malott (1990). Contudo um elemento novo para discussão ocorreu na condição de regras com prazos imediatos e consequências atrasadas. Os autores interpretaram esse último dado também com base nos efeitos do controle aversivo estabelecido pela comunidade verbal no seguimento de regras. Dizem os autores que embora o reforçamento atrasado não controle comportamento, a estipulação de prazos na instrução estabeleceria uma contingência de esquiva com reforço próximo, sendo essa regra a especificação de uma contingência que atuaria diretamente. A regra estabeleceria função aversiva para o comportamento de não seguimento. Então, quanto mais próximo do prazo estabelecido, tanto maior seria o efeito reforçador para o comportamento de esquiva.

Mistr e Glenn (1992), mais tarde, com seu estudo reiteraram a hipótese levantada por Braam e Malott (1990) para os dados inicialmente encontrados, porém pontuaram que a condição aversiva aprendida seria estabelecida pelo fato da formulação verbal funcionar como um Estímulo Especificador da Contingência (CSS). Dada aproximação conceitual denota, em alguma medida, um diálogo possível com a interpretação de Schlinger e Blakely (1987; Blakely \& Schlinger, 1987).

Ainda que o seguimento de uma regra não ocorra somente em função do controle aversivo exercido por um falante ${ }^{4}$, conforme parecem sugerir as análises prévias de Malott

\footnotetext{
${ }^{4}$ Hayes Zettle e Rosenfarb, (1989) sugeriram subtipos de comportamento governado por regras. De interesse, o operante chamado de rastreamento, é o comportamento governado por regras sobre o controle da aparente correspondência entre a regra e os eventos ambientais. Uma das características do rastreamento é que ele é influenciado pela história do ouvinte de contato com as consequências naturais por ter seguido a regra, pela correspondência entre essa regra e as outras regras ou eventos na história do ouvinte e pela importância da consequência implicada na regra. Sendo assim, um rastreamento poderia ser reforçado positivamente por colocar o ouvinte em contato com frações importantes do seu ambiente. Skinner (1957/1992) ao seu tempo
} 
(1988, 1989), a hipótese do autor pode ser bastante útil na análise de alguns tipos de comportamento governado por regras. Uma análise de contingências como a trazida por Braam e Malott (1990), sugere o histórico de reforçamento negativo para o seguimento de regras e o papel do reforçamento próximo na aquiescência do ouvinte. Essas poderiam ser também variáveis relevantes nos estudos sobre o controle verbal dos comportamentos de checagem (Arntz et al., 2007; Ladouceur et al., 1995; Ladouceur et al., 1997). Neles, a regra com especificação de alta responsabilidade pessoal poderia ter função de estímulo similar à função da regra com especificação de prazo de Braam e Malott (1990). A única diferença residiria no fato de que nos estudos sobre o comportamento de checagem a consequência aversiva especificada na instrução supostamente incidiria sobre outras pessoas (e.g., se o participante apresentar uma separação inefetiva das pílulas, as pessoas consumirão o remédio errado e por isso passarão mal), enquanto no estudo de Braam e Malott (1990) a consequência incidiria sobre as próprias crianças (e.g., se a criança não guardar os brinquedos no prazo solicitado, não poderá brincar depois na caixa mágica). Em comum, ambos os tipos de regras pareceram ter exercido um efeito de aumentar a frequência dos comportamentos de esquiva. Em última instância, ambos parecem ter especificado uma contingência de reforço negativo, em que o seguimento da regra seria consequenciado com a suspensão da condição aversiva.

Recentemente Abreu e Hübner (2011) apresentaram um estudo feito a partir do trabalho de Ladouceur e colaboradores de 1997, utilizando também instruções com

classificou um subtipo de mando, chamando-o de conselho. O conselho seria um mando em que o ouvinte experienciaria o reforçamento por responder a formulação verbal do falante. Mas o falante não participa diretamente da consequência. Semelhantemente ao que ocorre no rastreamento, o seguimento de um conselho poderia também ser reforçado positivamente. Em comum, parece que tanto o conselho como o rastreamento beneficiariam o ouvinte, e não o falante. 
especificações de consequências aversivas. No estudo de Abreu e Hübner (2011) dois participantes adultos do sexo feminino, verbalmente habilidosos e com 33 e 28 anos, foram convidados por terceiros a ajudar em uma tarefa de separação de sementes em uma loja de cereais. Quatro tipos de sementes de cores e dimensões semelhantes foram misturados em um saco plástico próprio para transporte: Feijão Bolinha, Feijão Fradinho, Grão de Soja e Tremoço Achatado. Os participantes realizaram a separação das sementes em uma mesa no centro do primeiro andar. A coleta aconteceu em um domingo, estando a loja fechada para os clientes. Na separação foram utilizados quatro potes de plástico semitransparentes com capacidade para dois litros.

Durante a separação foram contadas as respostas de checagem, definidas operacionalmente como verificação das sementes já separadas nos potes com função de se evitar erros. Na checagem as seguintes topografias de resposta foram registradas: a manipulação dentro do próprio pote, o despejar na mão ou mesa para nova conferência, o transferir as sementes erroneamente separadas de um pote para outro, o inclinar/mexer o pote para uma melhor visualização durante $2 \mathrm{~s}$ ou mais e a observação do pote por $2 \mathrm{~s}$ ou mais sem manipulação direta.

A sessão experimental teve duração de sessenta minutos, divididos em quatro fases de quinze minutos. Utilizou-se um delineamento sujeito único ABCA disposto da seguinte maneira:

Fase A / Linha de base: Foi apresentada pessoalmente a seguinte instrução para o participante - "Aqui estão quatro tipos de sementes nobres misturadas. Sua tarefa vai ser 
separar as quatro e colocá-las nesses quatro potes. Você terá uma hora para fazer isso. Eu vou estar em reunião lá e cima e por isso se precisar falar com você, farei pelo telefone”.

Fase B: Por telefone foi dada a seguinte instrução para o participante após 15 minutos transcorridos desde a instrução A - "Separe com muita atenção". Foi adicionado o autoclítico "muita" à instrução de separar com o objetivo de testar o controle verbal sobre o participante.

Fase C: Após 15 minutos transcorridos desde a instrução $\mathrm{B}$, foi apresentada a seguinte instrução, via telefone, com especificação de consequências aversivas: "Na verdade esse lote tem um tipo de semente que está com uma quantidade grande de agrotóxico que pode dar diarreia nas pessoas que comerem. Como essa mistura será fornecida para a merenda das crianças de uma escola, é muito importante que você as separe com muita atenção". Nessa fase foi adicionada a especificação de toda a contingência na instrução para a separação com o objetivo de testar o controle verbal sobre o participante.

Fase A / Reversão: Após 15 minutos transcorridos desde a instrução C, foi apresentada a seguinte instrução, via telefone, sem especificação de consequências aversivas: "Eu e meu chefe vimos que esse lote que você está separando é um lote mais antigo que não tem as sementes contaminadas. Então é só você separar as sementes”. Nessa fase foi dada a instrução com o objetivo de promover a reversão para uma frequência de respostas de checagem semelhantes à linha de base.

Seguindo o modelo de Laudouceur e colaboradores (1997) e de outros experimentos dessa área de investigação (Arntz, et al., 2007; Bouchard et al., 1999; Mancini et al., 2004; Ladouceur et al., 1995; Lopatka \& Rachman, 1995), somente ao final da sessão o 
experimentador revelou o estudo, explicando ao participante os objetivos e procedência da pesquisa com a solicitação de assinatura em termo de consentimento sobre o uso dos dados obtidos.

Como resultados, P1 apresentou quatro respostas de checagem na linha de base, nenhuma na fase de instrução com autoclítico, três respostas após a instrução com especificação de consequências aversivas e zero emissões na fase de reversão. Durante a entrevista final, P1 relatou ${ }^{5}$ que após ter recebido a primeira instrução foi estudando até descobrir um método para separar as sementes que pudesse lhe trazer melhores resultados. P2, ao seu turno, apresentou nenhuma checagem na linha de base, três na fase de instrução com autoclítico, quatro respostas após a instrução com especificação de consequências aversivas e uma emissão na fase de reversão.

Esses resultados mostraram que ambos os participantes apresentam notória variabilidade inter-sujeitos em relação à frequência de respostas de checagem. Como regularidades comportamentais, observou-se que os participantes aumentaram a frequência dos comportamentos de checagem na fase $\mathrm{C}$, sendo que $\mathrm{P} 1 \mathrm{o}$ fez em relação à fase $\mathrm{B}$ (instrução com autoclítico) e P2 em relação à linha de base. Igualmente semelhante, na fase de reversão, ambos diminuíram a frequência após apresentação da instrução sem especificação de consequências aversivas. P1 apresentou reversão total, e P2 reversão parcial.

\footnotetext{
${ }^{5}$ Após o final das fases o experimentador entrevistou pessoalmente os participantes com o objetivo de, se necessário, apenas complementar os dados empíricos. As informações levantadas pela entrevista não foram o foco principal na análise dos dados visto a falta de controle do método. Por esse motivo seus dados foram muito pouco utilizados. Entrevistas frequentemente permitem certo viés nas respostas verbais dos participantes devido ao múltiplo controle de estímulos envolvido. Alguns desses problemas podem ser evidenciados nas pesquisas sobre a correspondência entre o fazer e o relatar (c.f., Lloyd, 2002).
} 
Abreu e Hübner (2011) discutiram os dados dizendo que a instrução dada pelo experimentador na fase $\mathrm{C}$ especificou a consequência para uma separação não-efetiva das sementes. A especificação de toda a contingência funcionou como uma operação que estabeleceu o valor aversivo para o comportamento inefetivo, sendo este decorrente de um não seguimento da regra. A esquiva do evento aversivo envolveria simplesmente seguir a instrução, sendo portanto reforçada com a suspensão da provável consequência aversiva. Concluíram os autores que o seguimento das instruções pôde ser evidenciado através do aumento da frequência das respostas de checagem. Dadas respostas teriam a função de evitar os erros na separação das sementes.

No experimento outros dados também de interesse foram verificados a partir do emprego dos autoclíticos (Abreu \& Hübner, 2011). O autoclítico é uma unidade de comportamento verbal que depende de outro comportamento verbal para sua ocorrência, aumentando o controle daquela sobre o comportamento do ouvinte (Skinner, 1957/1992; Hübner, 2003; Hübner, Austin, \& Miguel, 2008). Pode, devido a essa particularidade, ser classificado como um operante verbal de ordem superior (Borloti, 2004). De acordo com Abreu e Hübner (2011), na fase B do estudo, o operante verbal "muita" poderia ser classificado com sendo um autoclítico quantificador do operante verbal de primeira ordem, no caso o operante "atenção". O autoclítico teve o efeito de modificar a reação do P2 na tarefa de separação das sementes. Esse participante apresentou um aumento na frequência das respostas de checagem. Contrariamente ao efeito esperado, P1 não apresentou respostas de checagem na apresentação da instrução. Não foi observado o aumento na frequência das checagens em relação à fase de linha de base, fato que, conforme pontuaram os autores, impediria até mesmo a identificação dessa instrução como exercendo função autoclítica. 
O trabalho de Abreu e Hübner (2011) foi um esforço inicial para trazer essa linha de pesquisa para a agenda da Análise Experimental do Comportamento. O estudo dos autores apresentou algumas limitações devido ao número de participantes adotado e pela variabilidade encontrada nas frequências das respostas de checagem. Esse fato impediria a generalidade dos dados obtidos. Contudo, algumas regularidades comportamentais foram encontradas em ambos os participantes como o aumento de frequência das checagens na fase $\mathrm{C}$ (em relação à fase $\mathrm{B}$ para $\mathrm{P} 1$ e à fase $\mathrm{A}$ para $\mathrm{P} 2$ ) e como a diminuição na fase de reversão. Novas pesquisas nesse campo serão necessárias na identificação mais precisa das variáveis experimentais. Um método experimental comparando o sujeito consigo próprio, sob o efeito de diferentes manipulações verbais, poderá ter o potencial de especificar mais claramente quais são os processos envolvidos no controle das respostas de checagem (Abreu \& Hübner, 2010).

\section{PROBLEMAS DE PESQUISA E EXPERIMENTOS PROPOSTOS}

Os Experimentos 1 e 2 se propuseram a ser uma variação metodológica do estudo inicial de Abreu e Hübner (2011). Com o objetivo de testar o controle de regras semelhantes às instruções adotadas pelos autores, foi usado um delineamento de grupo com reversão e controle de ordem inter-sujeitos (Cooper, Heron, \& Heward, 2007).

Segundo Cooper e colaboradores (2007) a combinação do delineamento de grupo inter-sujeitos e as táticas de reversão permitem uma demonstração mais convincente do controle experimental do que uma tática em isolado. Primeiro por que o delineamento inter- 
sujeitos permite que se obtenha um isolamento mais preciso do efeito das fases experimentais através da alteração sistemática de sua sequência entre diferentes participantes. Segundo porque o delineamento não abre mão do controle experimental intrasujeito, programado para ocorrer com a tática de reversão para cada participante.

Diferentemente ainda do estudo de Abreu e Hübner (2011), os Experimentos 1 e 2 utilizaram dez tipos de sementes com o objetivo de aumentar o custo de resposta na execução da tarefa. Outra mudança relevante foi o aumento do número de participantes, com o emprego de dezesseis adultos verbalmente habilidosos, sendo oito designados para cada experimento.

\section{EXPERIMENTO 1}

O objetivo do Experimento 1 foi testar (1) se uma instrução com especificação de consequência aversiva pode ter o efeito de produzir respostas de checagem; e (2) se após essa manipulação, seria possível produzir reversão com a apresentação de uma nova instrução verbal.

\section{MÉTODO}

\section{Participantes}

Oito participantes adultos, sendo sete mulheres e um homem, verbalmente habilidosos, entre 22 e 60 anos. 


\section{Ambiente experimental}

Os participantes realizaram a separação das sementes no segundo andar de um restaurante. Esse andar esteve vazio, sem a circulação de pessoas no recinto. Para separação foram utilizados dez potes de plástico opacos com capacidade para um litro cada. Os potes traziam etiqueta como nome das sementes. Os potes foram dispostos em cima de uma mesa de 120 X80 cm, colocada logo abaixo da câmera de segurança própria do estabelecimento. No início da separação, os potes já estavam parcialmente cheios em 1/3 de sua capacidade. Dez tipos de sementes de cores e dimensões semelhantes foram misturados em uma bacia retangular com capacidade para 20 litros (e.g., fava branca, feijão rajado, feijão bolinha, soja, feijão de corda, feijão carioca, feijão roxo, feijão branco, feijão jalo e feijão fradinho). As sementes foram misturadas em igual proporção.

\section{Procedimento}

$\mathrm{Na}$ ocasião do convite para participar da tarefa, os participantes não foram informados de que se tratava de um experimento de psicologia. Eles foram apenas convidados na rua por um auxiliar de pesquisa a ajudar em uma tarefa de separação de sementes em um restaurante, sendo conduzidos até o local. Foi instruído que o trabalho demandaria 45 minutos e que ganhariam $\mathrm{R} \$ 20,00$ como ajuda de custos ao final da tarefa. Igualmente aos experimentos anteriores (Abreu \& Hübner, 2011; Arntz et al., 2007; Ladouceur et al., 1995; Ladouceur et al., 1997), somente ao final da sessão o experimentador revelou o estudo, explicando ao participante os objetivos e procedência da pesquisa com a solicitação de assinatura em termo de consentimento sobre o uso dos dados obtidos. O termo de consentimento livre e esclarecido foi previamente aprovado pelo 
Conselho de Ética em Pesquisa HU/USP: 1161/11, sob o registro SISNEP CAAP: 0048.0.198.000-11 no Sistema Nacional de Ética em Pesquisa.

As sessões experimentais de 45 minutos foram divididas em três fases de 15 minutos. O tempo da apresentação das instruções não foi contabilizado vista a variação na diferença do tamanho das frases. $\mathrm{O}$ cronômetro foi iniciado ao final da apresentação da instrução e pausado ao término do tempo de cada fase. Com exceção da primeira instrução que foi feita pessoalmente, as outras instruções foram passadas por um telefone celular, dado pelo experimentador ao final da primeira instrução para fins de comunicação ao longo da tarefa. Depois de apresentada a primeira instrução, o experimentador foi para uma sala ao lado do recinto experimental, assistindo e gravando o desempenho do participante por meio de uma câmera do restaurante. Em um delineamento de grupo com reversão e controle de ordem inter-sujeitos, quatro sujeitos foram submetidos à sequência de fases $\mathrm{ABA}$, e outros quatro à sequência $\mathrm{BAB}$. Para a sequência de fases $\mathrm{ABA}$, as seguintes instruções foram assim dispostas:

Fase A: Foi apresentada pessoalmente a seguinte instrução para o participante - "[Nome do participante], aqui estão misturadas dez tipos de sementes nobres. Sua tarefa vai ser separálas e colocá-las nesses dez potes menores. Eu vou estar em reunião em outra sala, mas se precisar falar com você, farei por este telefone celular”.

Fase B (Especificação de consequência aversiva): Após 15 minutos transcorridos desde a instrução $\mathrm{A}$, por telefone foi apresentada a seguinte instrução com especificação de consequência aversiva: "[Nome do participante], essas sementes vão ser fornecidas para a 
merenda das crianças de uma escola. Por isso, se encontrar erros na separação, meu chefe pode querer descontar dinheiro dos seus R \$ 20,00”.

Fase A: Após 15 minutos transcorridos desde a instrução $\mathrm{B}$, por telefone foi apresentada a seguinte instrução para a reversão: "[Nome do participante], eu e meu chefe vimos que esse é um lote mais antigo que não irá para a merenda das crianças. Então é só você separar as sementes. Daremos garantidos seus R\$ 20,00 no final”.

A Tabela 1 apresenta a sequência das fases programadas para cada participante:

\begin{tabular}{cccc}
\hline Fase A & Fase B & Fase A \\
Participante & $\begin{array}{c}\text { Instrução para a } \\
\text { separação das } \\
\text { sementes }\end{array}$ & $\begin{array}{c}\text { Instrução com } \\
\text { especificação de } \\
\text { consequência } \\
\text { aversiva }\end{array}$ & $\begin{array}{c}\text { Instrução para a } \\
\text { separação das } \\
\text { sementes }\end{array}$ \\
\hline P1 & 15 min & 15 min & 15 min \\
P3 & 15 min & 15 min & 15 min \\
P5 & 15 min & 15 min & 15 min \\
P7 & & & 15 min \\
\hline
\end{tabular}

Tabela 1 - Apresentação da sequência das fases programadas para cada participante, num total de 45 minutos de sessão experimental. O delineamento ABA foi dividido em três períodos de 15 minutos. Inicialmente foi apresentada a instrução referente à separação das sementes / linha de base (Fase A); após 15 minutos transcorridos desde a instrução A, foi apresentada a instrução com especificação de consequência aversiva (Fase B); e após 15 minutos transcorridos desde a instrução B, foi apresentada a instrução para a separação das sementes / reversão (Fase A). O tempo total da sessão excluiu as pausas no cronômetro no momento da apresentação das instruções. 
Para os quatro participantes que foram submetidos à sequência de fases BAB, instruções semelhantes foram apresentadas. Contudo a sessão experimental iniciou e finalizou com as fases de instrução com especificação de consequência aversiva (e.g., fases B). A sequência de apresentação das instruções foi disposta da seguinte forma:

Fase B (Especificação de consequência aversiva): Foi apresentada pessoalmente a seguinte instrução para o participante - "[Nome do participante], essas sementes vão ser fornecidas para a merenda das crianças de uma escola. Por isso, se encontrar erros na separação, meu chefe pode querer descontar dinheiro dos seus $\mathrm{R} \$ 20,00$. Eu vou estar em reunião em outra sala, mas se precisar falar com você, farei por este telefone celular”.

Fase A: Após 15 minutos transcorridos desde a instrução $\mathrm{B}$, por telefone foi apresentada a seguinte instrução para a separação das sementes: “[Nome do participante], eu e meu chefe vimos que esse é um lote mais antigo que não irá para a merenda das crianças. Então é só você separar as sementes. Daremos garantidos seus R\$ 20,00 no final”.

Fase B (Especificação de consequência aversiva): Após 15 minutos transcorridos desde a instrução A, por telefone foi apresentada novamente a instrução com especificação de consequência aversiva: "Desculpe, eu me enganei. Esse lote é o que realmente vai para a merenda da escola. Por isso, se encontrar erros na separação, meu chefe pode querer descontar dinheiro dos seus R\$20,00”. 
A Tabela 2 apresenta a sequência das fases programadas para cada participante:

\begin{tabular}{cccc}
\hline Participante & $\begin{array}{c}\text { Fase A } \\
\text { Instrução com } \\
\text { especificação de } \\
\text { consequência } \\
\text { aversiva }\end{array}$ & $\begin{array}{c}\text { Instrução para a } \\
\text { separação das } \\
\text { sementes }\end{array}$ & $\begin{array}{c}\text { Instrução com } \\
\text { especificação de } \\
\text { consequência } \\
\text { aversiva }\end{array}$ \\
\hline P2 & 15 min & 15 min & 15 min \\
P4 & 15 min & 15 min & 15 min \\
P6 & 15 min & 15 min & 15 min \\
\hline
\end{tabular}

Tabela 2 - Apresentação da sequência das fases programadas para cada participante, num total de 45 minutos de sessão experimental. O delineamento BAB foi dividido em três períodos de 15 minutos. Inicialmente foi apresentada a instrução com especificação de consequência aversiva / linha de base (Fase B); após 15 minutos transcorridos desde a instrução B, foi apresentada a instrução para a separação das sementes (Fase A); e após 15 minutos transcorridos desde a instrução A, foi apresentada a instrução com especificação de consequência aversiva / reversão (Fase B). O tempo total da sessão excluiu as pausas no cronômetro no momento da apresentação das instruções.

Embora a instrução de linha de base seja topograficamente diferente da última instrução de reversão, o critério que permitiu correlacioná-los no delineamento $\mathrm{ABA}$ ou BAB adotado foi o efeito de reversão exercido sobre as respostas de checagem. Portanto, preencheu-se um critério funcionalmente-orientado para a reversão (Abreu \& Hübner, 2011). 


\section{Variável Dependente}

Como dimensão da variável dependente no Experimento 1, foram mensuradas as porcentagens das respostas de checagem de cada fase. As respostas de checagem são definidas operacionalmente como sendo a verificação das sementes já separadas nos potes com função de evitar ou corrigir erros. Na checagem as seguintes topografias de resposta foram registradas: a manipulação dentro do pote sem separação de sementes, isto é, a retirada de uma das sementes; o despejar na mão ou mesa e retirada de uma semente de um grupo já separado; o tirar uma semente de um pote; o transferir a semente erroneamente separada de um pote para outro; o inclinar/mexer o pote para uma melhor visualização durante $2 \mathrm{~s}$ ou mais; e a observação do pote por $2 \mathrm{~s}$ ou mais sem manipulação direta.

\section{RESULTADOS}

A Figura 1 apresenta as porcentagens das respostas de checagem do Experimento 1, sequência de fases ABA, para os participantes P1, P3, P5 e P7. 
Participante 1

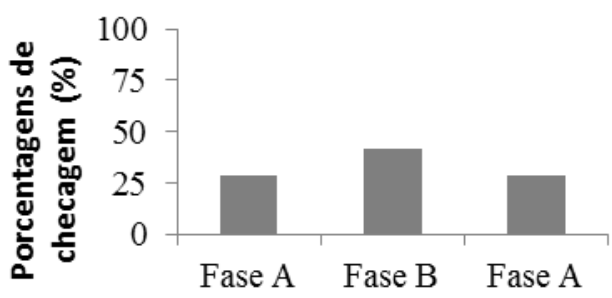

Participante 5

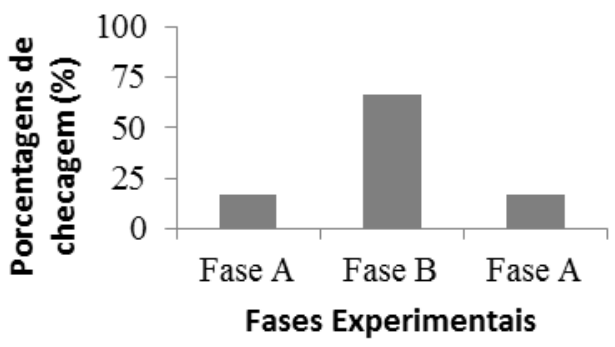

Participante 3

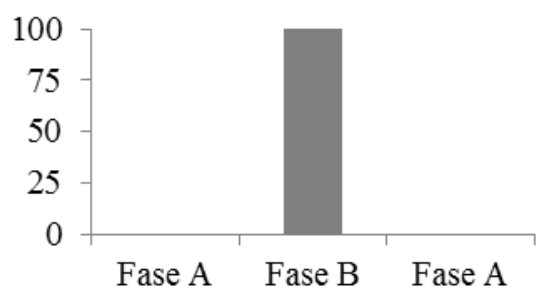

Participante 7

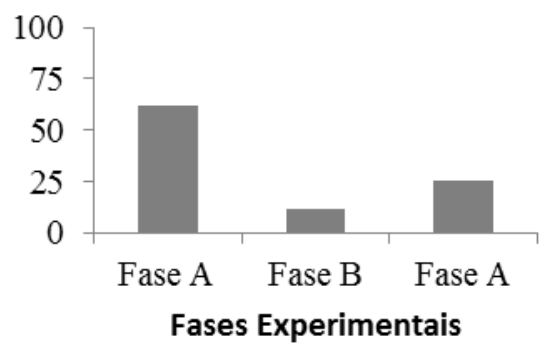

Figura 1 - Porcentagens das respostas de checagem apresentadas pelos participantes P1, P3, P5 e P7 ao longo das fases experimentais ABA do Experimento 1. Cada fase experimental foi programada para demandar 15 minutos.

P1 apresentou $29 \%$ das respostas de checagem na fase A, $42 \%$ na fase B de apresentação da instrução com especificação de consequência aversiva, retornando para $29 \%$ das checagens na fase A de reversão.

P3 apresentou $0 \%$ das respostas checagens na fase $\mathrm{A}, 100 \%$ na fase $\mathrm{B}$ e $0 \%$ na fase

A.

P5 apresentou 17\% das respostas de checagem na fase A, aumentando para $66 \%$ na fase $\mathrm{B}$, e retornando para $17 \%$ na fase $\mathrm{A}$ de reversão. 
P7 apresentou $62 \%$ das respostas de checagem na fase A, diminuindo para $12 \%$ na fase B para, a seguir, aumentar para $26 \%$ de checagens na fase A de reversão.

Como efeito comum entre os participantes, observa-se uma maior porcentagem das respostas de checagem nas fases B (de instrução com especificação de consequência aversiva) para P1, P3 e P5, com 42\%, 100\% e 66\% das checagens, respectivamente. Diferentemente, na fase B, o P7 apresentou 12\% das checagens, sendo essa a menor porcentagem apresentada por esse participante em uma fase.

Para os participantes que apresentaram as maiores porcentagens de checagens nas fases B, observa-se efeito de reversão total na fase A, no comportamento de P1, P3 e P5, com $29 \%, 0 \%$ e $17 \%$ das checagens, respectivamente. Essas porcentagens são exatamente as mesmas apresentadas por esses participantes nas fases A de linha de base.

A Figura 2 apresenta as porcentagens das respostas de checagem do Experimento 1, sequência de fases BAB, para os participantes P2, P4, P6 e P8. 

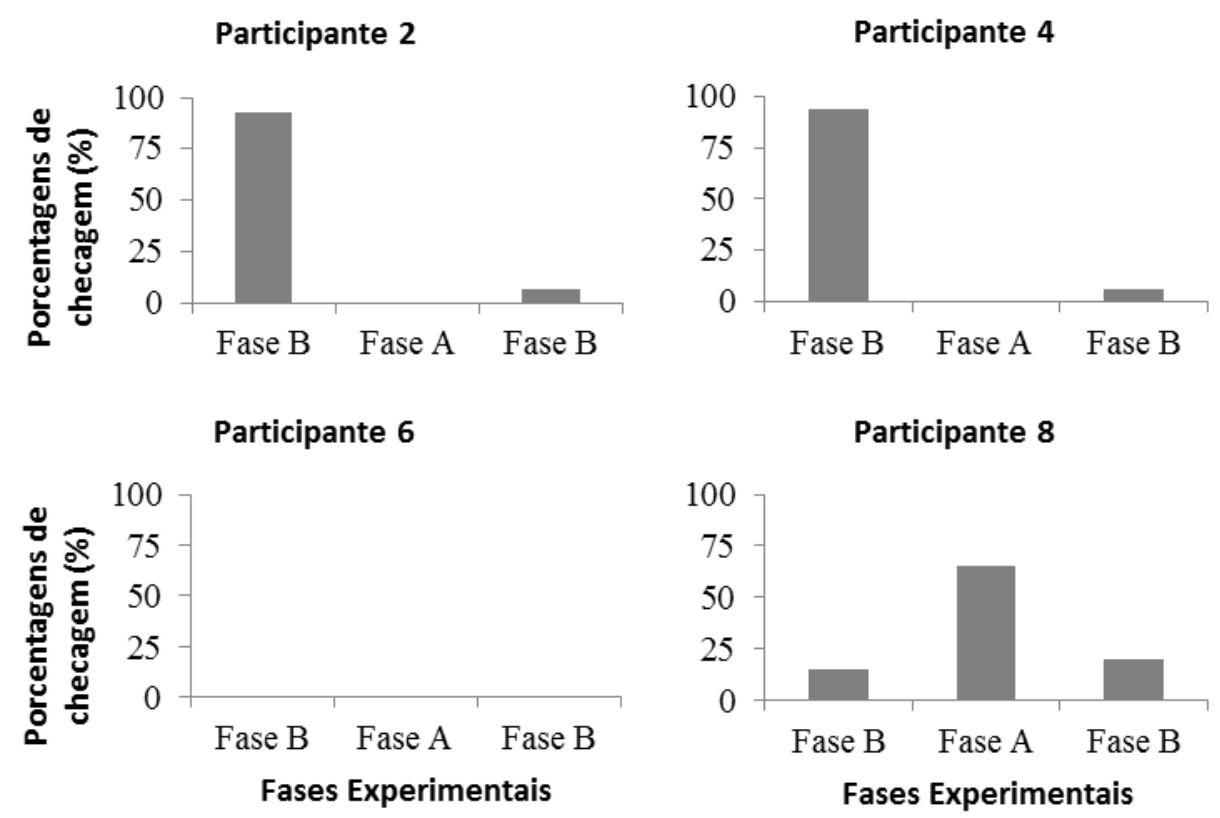

Figura 2 - Porcentagens das respostas de checagem apresentadas pelos participantes P2, P4, P6 e P8 ao longo das fases experimentais BAB do Experimento 1. Cada fase experimental foi programada para demandar 15 minutos.

P2 apresentou $93 \%$ das respostas de checagem na fase B, $0 \%$ na fase $\mathrm{A}$, e $7 \%$ das checagens na fase B de reversão.

P4 apresentou $94 \%$ das respostas de checagem na fase B, $0 \%$ na fase A e $6 \%$ das checagens na fase B de reversão.

P6 não apresentou checagem ao longo das fases experimentais BAB.

P8 apresentou $15 \%$ das respostas de checagem na fase B, aumentando para $65 \%$ na fase A para, a seguir, diminuir para $20 \%$ das checagens na fase B de reversão.

Como efeito comum entre os participantes, observa-se que há uma maior porcentagem de respostas de checagem nas fases B (de instrução com especificação de 
consequência aversiva) para $\mathrm{P} 2$ e $\mathrm{P} 4$, com respectivamente, $93 \%$ e $94 \%$ nas fases B de linha de base, $7 \%$ e $6 \%$ nas fases B de reversão.

Diferentemente dos outros participantes, P6 não apresenta qualquer emissão de respostas de checagem ao longo das fases experimentais. Já P8 apresenta uma maior porcentagem na fase A de instrução para separação em relação às fases B de linha de base e reversão.

Para P2 e P4 que apresentam as maiores porcentagens de checagens nas fases B, observa-se ainda uma expressiva menor porcentagem das checagens na fase B de reversão comparativamente com as fases B de linha de base (B93\% - B7\% e B94\% - B6\%, respectivamente).

\section{Concordância entre os Observadores}

No Experimento 1, com o uso da gravação em vídeo, um segundo observador independente também fez as medições das respostas de checagem apresentadas pelos participantes. O acordo foi obtido a partir do tempo integral de cada fase. Para cada participante foi feito então o cálculo de concordância entre os observadores (CEO), do tipo média de contagem por intervalo (Cooper et al., 2007), através da fórmula [(CEO fase $1+$ CEO fase $2+$ CEO fase 3) / 3 fases] X 100. A Tabela 3 mostra as porcentagens médias de acordo entre observadores: 


\begin{tabular}{|c|c|c|c|c|c|}
\hline \multirow[b]{2}{*}{ Participante } & \multicolumn{3}{|c|}{ Condição } & \multirow[b]{2}{*}{ Amplitude } & \multirow[b]{2}{*}{ CEO média } \\
\hline & CEO fase A & CEO fase $\mathrm{B}$ & CEO fase $\mathrm{A}$ & & \\
\hline $\mathrm{P} 1$ & 94 & 100 & 87 & $87-100$ & 94 \\
\hline P3 & 100 & 93 & 100 & $93-100$ & 98 \\
\hline P5 & 100 & 100 & 100 & & 100 \\
\hline \multirow[t]{2}{*}{ P7 } & 100 & 100 & 100 & & 100 \\
\hline & CEO fase B & CEO fase A & CEO fase B & & \\
\hline $\mathrm{P} 2$ & 96 & 100 & 100 & $96-100$ & 99 \\
\hline P4 & 85 & 100 & 100 & $85-100$ & 95 \\
\hline P6 & 100 & 100 & 100 & & 100 \\
\hline P8 & 100 & 100 & 100 & & 100 \\
\hline
\end{tabular}

Tabela 3. Amplitude e porcentagem média de concordância entre observadores para cada participante do Experimento 1.

\section{DISCUSSÃO}

No Experimento 1, cinco de oito participantes apresentaram maiores porcentagens de checagens sob especificação de consequência aversiva. Sobre a propriedade de evocar as respostas especificadas, Schlinger e Blakely (1987; Blakely \& Schlinger, 1987) pontuam que uma regra não pode ter função de SD para o seu seguimento, pois antes, ela altera a função dos estímulos especificados na formulação verbal. Dessa forma, no comportamento governado por regras os autores aproximam os efeitos comportamentais do estímulo verbal dos efeitos alteradores de função do condicionamento operante e respondente. Por esse motivo, ao invés do termo regra, os autores adotaram o termo Estímulo Especificador da Contingência (CSS) (Blakely \& Schlinger, 1987; Schlinger e Blakely, 1987), e mais recentemente, operação verbal alteradora de função (Schlinger 2008a; 2008b). Um CSS 
produz mudanças nos estímulos especificados pela regra, sendo eles estímulos discriminativos, eliciadores, operações estabelecedoras (OEs) ou estímulos consequentes. Nos presentes experimentos, opta-se por adotar o termo CSS, visto a especificação da contingência, embora Schlinger (1993; 2008a; 2008b) tenha ressaltado mais recentemente a não necessidade de qualquer requerimento formal como a especificação da contingência de reforçamento no estímulo verbal.

No Experimento 1, ainda que os CSSs apresentados pessoalmente (e.g., fase de linha de base) ou por telefone (e.g., outras fases) tenham controlado o comportamento de separação como evento antecedente, sua a característica principal é alterar a função estabelecedora e discriminativa de estímulos previamente neutros, fortalecendo ou enfraquecendo as relações que dados estímulos guardam com as respostas de checagem. Assim, a estimulação proprioceptiva aversiva da resposta inefetiva de separação (e.g., eliciada pelo histórico de pareamento das respostas com consequências que levaram a punições sociais por não terem atingido certos critérios de desempenho) e os erros contidos nos potes (e.g., colocar o feijão branco no bote da fava branca) controlaram uma maior porcentagem das respostas de checagem.

O seguimento dos CSSs com a especificação de consequência aversiva para a resposta inefetiva de separação pode ser evidenciado através do aumento da porcentagem das respostas de checagem nas fases B. Houve o aumento da porcentagem para P1, P3, P5 (ABA) e P2, P4 (BAB). Os CSSs apresentados nas fases B funcionam como uma operação que estabelece maior valor aversivo para a resposta inefetiva de separação, sendo este um comportamento incompatível com o desempenho especificado. Os CSSs também 
fortalecem a função discriminativa que os estímulos relacionados aos erros de separação mantêm com as respostas de checagem. Para esquivar ou fugir do evento aversivo, frente a essa estimulação discriminativa, os participantes precisam simplesmente seguir os CSSs, tendo suas respostas reforçadas ao final do experimento por evitar a consequência da perda de dinheiro. As respostas controladas pelos CSSs têm, portanto, a função de corrigir ou evitar os erros na separação das sementes.

Para os participantes que apresentaram maiores porcentagens das checagens nas fases B, observa-se efeito de reversão total no comportamento de P1, P3 e P5, para o delineamento ABA. Essas porcentagens são exatamente as mesmas apresentadas por esses participantes nas fases A de linha de base. Já no delineamento BAB, P2 e P4 apresentaram reversão parcial, com uma expressiva diferença de porcentagens entre as fases B de linha de base e B de reversão. Segundo Catania (1998/1999) "efeitos reversíveis são mudanças na performance que são eliminadas, imediatamente ou algum tempo depois, quando as operações que a produzem são descontinuadas (eg., se o responder retorna ao nível inicial após a punição, os efeitos da punição são reversíveis)" (p. 408). Sendo assim, o efeito de um CSS da fase B com a especificação de uma consequência aversiva (e.g., "[... Por isso, se encontrar erros na separação, meu chefe pode querer descontar dinheiro dos seus $R \$$ 20,00") pode estar sendo revertido com a apresentação e seguimento de um novo CSS, no caso o A, especificador da suspensão da consequência futura (e.g., "[...] eu e meu chefe vimos que esse é um lote mais antigo que não irá para a merenda das crianças. Então é só você separar as sementes. Daremos garantidos seus $R \$ 20,00$ no final"). 
No Experimento 1 há ainda um menor seguimento dos CSSs apresentados nas fases B pelo P7 (ABA), P6 e P8 (BAB). P7 e P8 apresentaram menores porcentagens das respostas de checagem e P6 apresentou nenhuma resposta. P7 e P8 apresentaram ainda maiores frequências nas fases A (A62\% - A26\%, A65\%, respectivamente). Esses dados sugerem que os CSSs das fases B enfraqueceram a função estabelecedora e discriminativa das circunstâncias relacionadas aos erros de separação, ou mesmo que pode ter havido um maior controle pelas contingências ao longo das fases, em comparação com o controle verbal.

P6, ao seu turno, separou as sementes em porções no tampo da mesa, não chegando a transferir para os potes. Na sessão "método" do presente estudo as respostas de checagem foram definidas operacionalmente como sendo a verificação das sementes já separadas nos potes com função de corrigir ou evitar erros. Esse cuidado experimental foi implementado com o objetivo de criar um critério estável para o registro das respostas de separação, bem como também facilitar a contagem das respostas de checagem, dirimindo eventuais ambiguidades interpretativas entre os observadores. Por esse motivo, as respostas de P6 não foram contadas, visto a necessidade da separação prévia efetiva nos potes, de onde as checagens seriam então registradas.

\section{EXPERIMENTO 2}

O Experimento 2 teve como objetivo (1) reproduzir algumas fases do Experimento

1 proposto (e.g., fases de reversão) e (2) testar se uma instrução com especificação de 
consequência apetitiva poderia ter o efeito de produzir respostas de checagem. Por esse motivo, o Experimento 2 teve também o objetivo de testar a hipótese da emissão das respostas de checagem sob contextos apetitivos, fato que, se confirmado, poderia questionar o modelo de TOC puramente embasado na hipótese do controle aversivo (c.f., Dollard \& Miller, 1950).

\section{MÉTODO}

\section{Participantes}

Oito participantes adultos, sendo seis mulheres e dois homens, verbalmente habilidosos, entre 16 e 65 anos.

\section{Ambiente experimental}

O mesmo adotado no Experimento 1

\section{Procedimento}

O convite para participar da tarefa de separação foi o mesmo do Experimento 1. Ao final da tarefa houve um único diferencial adotado para os participantes da sequência BAB. Esses participantes receberam $\mathrm{R} \$ 10,00$ como prêmio extra, conforme anunciado durante o experimento.

O Experimento 2 apresentou instruções com especificação de consequência apetitiva, no caso, o anúncio do ganho de um "dinheiro extra caso não houvesse erros na separação". Em um delineamento de grupo com reversão e controle de ordem inter- 
sujeitos, quatro sujeitos foram submetidos as sequência de fases $\mathrm{ABA}$, e outros quatro a sequência $\mathrm{BAB}$. Para sequência de fases $\mathrm{ABA}$, as seguintes instruções foram assim dispostas:

Fase A: Foi apresentada pessoalmente a seguinte instrução para o participante - "[Nome do participante], aqui estão misturadas dez tipos de sementes nobres. Sua tarefa vai ser separálas e colocá-las nesses dez potes menores. Eu vou estar em reunião em outra sala, mas se precisar falar com você, farei por este telefone celular".

Fase B (Especificação de consequência apetitiva): Foi dada a seguinte instrução por telefone após 15 minutos transcorridos desde a instrução A - "Esse lote de sementes será fornecido para a merenda das crianças de uma escola. Então eu the darei um dinheiro extra se não tiver erros na sua separação".

Fase A: Após 15 minutos transcorridos desde a instrução $\mathrm{B}$, foi apresentada a seguinte instrução via telefone: "[Nome do participante], eu e meu chefe vimos que esse é um lote mais antigo que não irá para a merenda das crianças. Então é só você separar as sementes. Daremos garantidos seus R $\$ 20,00$ no final". 
A Tabela 4 apresenta a sequência das fases programadas para cada participante:

\begin{tabular}{cccc}
\hline Fase A & $\begin{array}{c}\text { Fase B } \\
\text { Instrução com } \\
\text { Participante }\end{array}$ & $\begin{array}{c}\text { Instrução para } \\
\text { sepação das } \\
\text { sementes } \\
\text { consequência } \\
\text { apetitiva }\end{array}$ & $\begin{array}{c}\text { Instrução para a } \\
\text { separação das } \\
\text { sementes }\end{array}$ \\
\hline P9 & 15 min & 15 min & 15 min \\
P11 & 15 min & 15 min & 15 min \\
P13 & 15 min & 15 min & 15 min \\
\hline
\end{tabular}

Tabela 4 - Apresentação da sequência das fases programadas para cada participante, num total de 45 minutos de sessão experimental. O delineamento ABA foi dividido em três períodos de 15 minutos. Inicialmente foi apresentada a instrução referente à separação das sementes / linha de base (Fase A); após 15 minutos transcorridos desde a instrução A, foi apresentada a instrução com especificação de consequência apetitiva (Fase B); e após 15 minutos transcorridos desde a instrução B, foi apresentada a instrução para a separação das sementes / reversão (Fase A). O tempo total da sessão excluiu as pausas no cronômetro no momento da apresentação das instruções.

Para os quatro participantes que foram submetidos à sequência de fases $B A B$, instruções semelhantes foram apresentadas. Contudo a sessão experimental iniciou e finalizou com as fases de instrução com especificação de consequência apetitiva (e.g., fases B). A sequência de apresentação das instruções foi disposta da seguinte forma:

Fase B (Especificação de consequência apetitiva): Foi apresentada pessoalmente a seguinte instrução - “[Nome do participante], essas sementes vão ser fornecidas para a merenda das crianças de uma escola. Então eu lhe darei um dinheiro extra se não tiver erros na sua 
separação. Eu vou estar em reunião em outra sala, mas se precisar falar com você, farei por este telefone celular".

Fase A: Após 15 minutos transcorridos desde a instrução $\mathrm{B}$, por telefone foi apresentada a seguinte instrução para a separação das sementes: “[Nome do participante], eu e meu chefe vimos que esse é um lote mais antigo que não irá para a merenda das crianças. Então é só você separar as sementes. Daremos garantidos seus R\$20,00 no final".

Fase B (Especificação de consequência apetitiva): Após 15 minutos transcorridos desde a instrução A, por telefone foi apresentada novamente a instrução com especificação de consequência apetitiva: "[Nome do participante], desculpe, eu me enganei. Esse lote é o que realmente vai para a merenda da escola. Por isso, darei um dinheiro extra se não tiver erros na sua separação". 
A Tabela 5 apresenta a sequência das fases programadas para cada participante:

\begin{tabular}{cccc}
\hline Fase B & Fase A & Fase B \\
Participante & $\begin{array}{c}\text { Instrução com } \\
\text { especificação de } \\
\text { consequência } \\
\text { apetitiva }\end{array}$ & $\begin{array}{c}\text { Instrução para a } \\
\text { separação das } \\
\text { sementes }\end{array}$ & $\begin{array}{c}\text { Instrução com } \\
\text { especificação de } \\
\text { consequência } \\
\text { apetitiva }\end{array}$ \\
\hline P10 & 15 min & 15 min & 15 min \\
P12 & 15 min & 15 min & 15 min \\
P16 & 15 min & 15 min & 15 min \\
\hline
\end{tabular}

Tabela 5 - Apresentação da sequência das fases programadas para cada participante, num total de 45 minutos de sessão experimental. O delineamento BAB foi dividido em três períodos de 15 minutos. Inicialmente foi apresentada a instrução com especificação de consequência apetitiva / linha de base (Fase B); após 15 minutos transcorridos desde a instrução $\mathrm{B}$, foi apresentada a instrução para a separação das sementes (Fase A), e após 15 minutos transcorridos desde a instrução A, foi apresentada a instrução com especificação de consequência apetitiva / reversão (Fase B). O tempo total da sessão excluiu as pausas no cronômetro no momento da apresentação das instruções.

\section{Variável Dependente}

Ao longo de todas as fases do Experimento 2, a dimensão da variável dependente mensurada foi a mesma do Experimento 1. Foram registradas as porcentagens das respostas de checagem de cada fase. 


\section{RESULTADOS}

A Figura 3 apresenta as porcentagens das respostas de checagem do Experimento 2, para a sequência de fases $\mathrm{ABA}$.
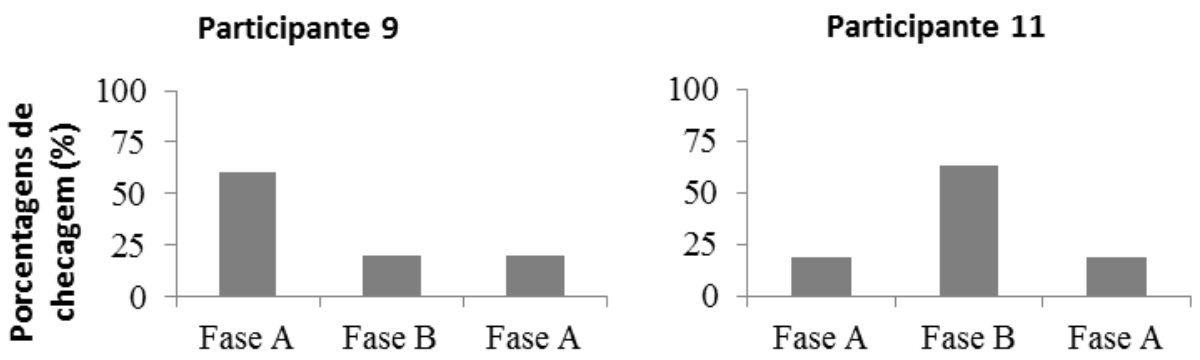

Participante 13

Participante 15
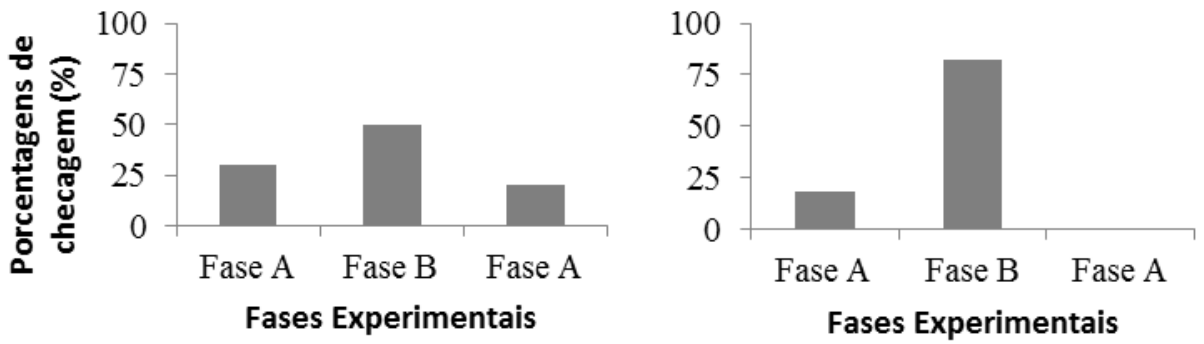

Figura 3 - Porcentagens das respostas de checagem apresentadas pelos participantes P9, P11, P13 e P15 ao longo das fases experimentais ABA do Experimento 2. Cada fase experimental foi programada para demandar 15 minutos.

P9 apresentou $60 \%$ das respostas de checagem na fase A, $20 \%$ na fase B de apresentação da instrução com especificação de consequência apetitiva, e $20 \%$ das checagens na fase A de reversão.

P11 apresentou 19\% das respostas checagens na fase A, $63 \%$ na fase B, diminuindo a seguir para $19 \%$ na fase $\mathrm{A}$. 
P13 apresentou 30\% das respostas de checagem na fase A, aumentando para $50 \%$ na fase B, e retornando para $20 \%$ na fase A de reversão.

P15 apresentou 18\% das respostas de checagem na fase A, aumentando para $82 \%$ na fase B para, a seguir, diminuir para $0 \%$ das checagens na fase A de reversão.

Como efeito comum entre os participantes, observa-se que há uma maior porcentagem de respostas de checagem nas fases B (de instrução com especificação de consequência apetitiva) para P11, P13 e P15, com 63\%, 50\% e 82\% das checagens, respectivamente.

Diferentemente, P9 na fase B apresentou a menor porcentagem de checagens, com 20\%. Essa mesma porcentagem se repetiu na fase A seguinte de reversão.

Para os participantes que apresentaram as maiores porcentagens de checagens nas fases B, observa-se efeito de reversão total na fase $\mathrm{A}$ de reversão nas respostas de P11, onde retornou para 19\% das checagens. Esse índice é igual ao apresentado na fase A de linha de base (A19\% - A19\%). O P13 e o P15 apresentaram reversão parcial (A30\% $\mathrm{A} 20 \%$ e A18\% - A0\%, respectivamente). 
A Figura 4 mostra as porcentagens das respostas de checagem do Experimento 2, para a sequência de fases BAB.
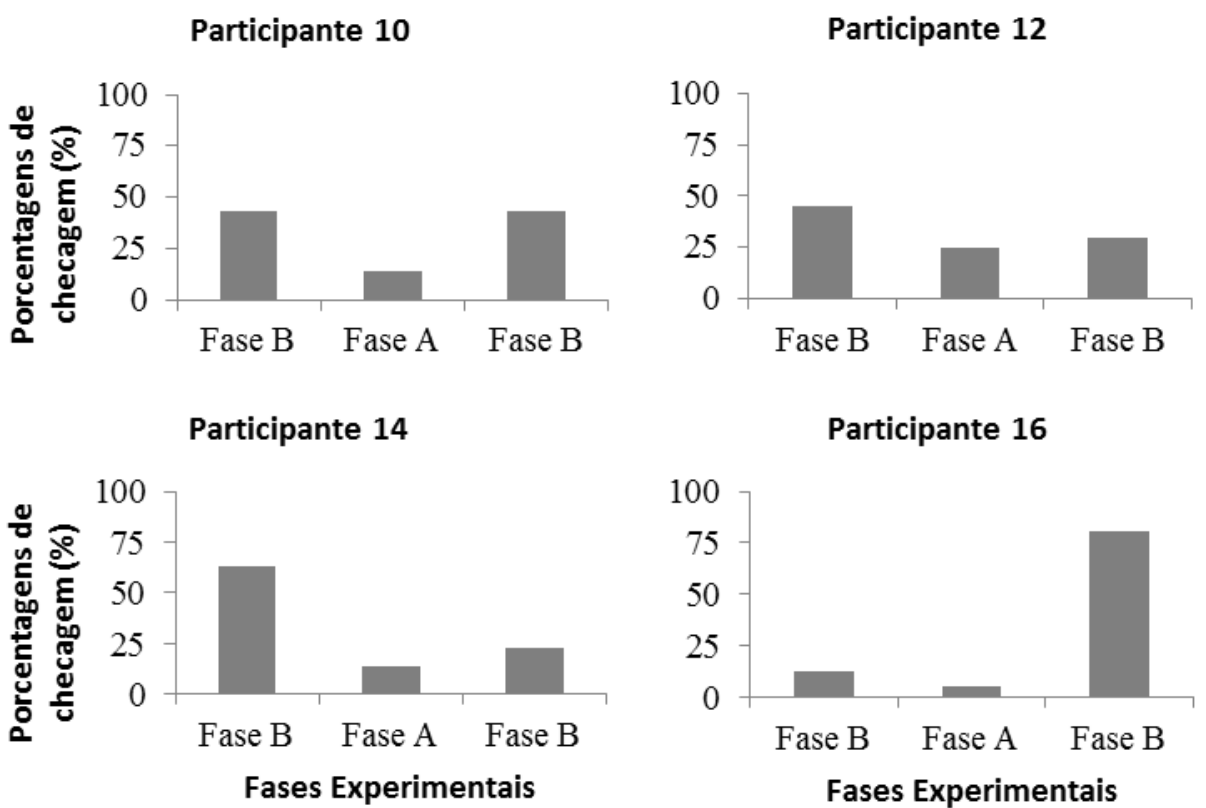

Figura 4 - Porcentagens das respostas de checagem apresentadas pelos participantes P10, P12, P14 e P16 ao longo das fases experimentais BAB do Experimento 2. Cada fase experimental foi programada para demandar 15 minutos.

P10 apresentou $43 \%$ das respostas de checagem na fase B, $14 \%$ na fase A, e $43 \%$ das checagens na fase B de reversão.

P12 apresentou $45 \%$ das respostas de checagem na fase B, $25 \%$ na fase A e $30 \%$ das checagens na fase B de reversão.

P14 apresentou $63 \%$ das respostas de checagem na fase B, diminuindo para $14 \%$ na fase A para, a seguir, aumentar para 23\% das checagens na fase B de reversão. 
P16 apresentou 13\% das respostas de checagem na fase B, diminuindo para 5\% na fase A para, a seguir, aumentar para $81 \%$ das checagens na fase B de reversão.

Como efeito comum entre os participantes há uma maior porcentagem de respostas de checagem nas fases B (de instrução com especificação de consequência apetitiva) para $\mathrm{P} 10, \mathrm{P} 12, \mathrm{P} 14$ e P16, com respectivamente 43\%, 45\%, 63\% e 13\% nas fases B de linha de base, e $43 \%, 30 \%, 23 \%$ e $81 \%$ nas fases B de reversão.

Nesses participantes com as maiores porcentagens de checagens nas fases B, observa-se que P10 apresentou reversão total na fase B de reversão (B43\% - B43\%) e P12 apresentou reversão parcial (B45\% - B30\%). P14 e P16, ao seu turno, apresentaram reversão parcial, mas com expressiva diferença de porcentagens (B63\% - B23\% e B13\% B81\%, respectivamente).

\section{Concordância entre Observadores}

Similarmente ao Experimento 1, com o uso da gravação em vídeo, um observador independente também fez a medição das respostas de checagem apresentadas por cada participante. A fórmula para o cálculo do CEO foi igual à utilizada no Experimento 1. A Tabela 6 mostra as porcentagens médias de concordância entre observadores do Experimento 2 , do tipo média de contagem por intervalo: 


\begin{tabular}{|c|c|c|c|c|c|}
\hline \multirow[b]{2}{*}{ Participante } & \multicolumn{3}{|c|}{ Condição } & \multirow[b]{2}{*}{ Amplitude } & \multirow[b]{2}{*}{ CEO média } \\
\hline & CEO fase A & CEO fase $\mathrm{B}$ & CEO fase A & & \\
\hline P9 & 100 & 100 & 100 & & 100 \\
\hline P11 & 100 & 100 & 83 & $83-100$ & 94 \\
\hline $\mathrm{P} 13$ & 100 & 100 & 100 & & 100 \\
\hline \multirow[t]{2}{*}{ P15 } & 100 & 90 & 100 & $90-100$ & 97 \\
\hline & CEO fase B & CEO fase A & CEO fase $\mathrm{B}$ & & \\
\hline P10 & 100 & 100 & 83 & $83-100$ & 94 \\
\hline $\mathrm{P} 12$ & 95 & 92 & 100 & $92-100$ & 96 \\
\hline P14 & 94 & 100 & 100 & $94-100$ & 98 \\
\hline P16 & 87 & 100 & 88 & $87-100$ & 92 \\
\hline
\end{tabular}

Tabela 6. Amplitude e porcentagem média de concordância entre observadores para cada participante do Experimento 2.

\section{DISCUSSÃO}

No Experimento 2, sete de oito participantes apresentaram maiores porcentagens de checagens sob instruções com especificação de consequência apetitiva. Essas instruções também funcionaram como Estímulos Especificadores de Contingência (CSSs) (Schlinger \& Blakely, 1987; Blakely \& Schlinger, 1987) pelo fato de alterar a função dos estímulos especificados na formulação verbal. Assim, os CSSs com especificação de consequência apetitiva fortaleceram a função discriminativa dos erros de separação das sementes passando a evocar um maior número de respostas de checagem (e.g., o feijão branco colocado no pote da fava branca passa a sinalizar o erro de separação, evocando a resposta de checagem com função de produzir o acerto com ganho do dinheiro extra). 
Para o delineamento ABA, observa-se que houve uma maior porcentagem de respostas de checagem nas fases B para P11, P13 e P15. Já no delineamento BAB, todos os participantes apresentaram maiores porcentagens de checagem nas fases B em comparação com as fases A (e.g., P10, P12, P14 e P16). Esses dados mostram que os CSSs com especificação de consequência apetitiva fortalecem a relação discriminativa entre os erros de separação e as resposta de checagem. Para produzir o reforçamento positivo especificado, frente a essa estimulação discriminativa, os participantes precisaram seguir o CSS, tendo suas respostas reforçadas ao final do experimento. As respostas controladas pelos CSSs e pelos erros de separação têm, portanto, a função de produzir o dinheiro extra. O seguimento dos CSSs pode ser evidenciado por meio do aumento da porcentagem das respostas de checagem nas fases B para P11, P13 e P15 (ABA), e P10, P12, P14, P16 (BAB).

Para os participantes que apresentaram maiores porcentagens das checagens nas fases B, observa-se no delineamento ABA efeito de reversão total nas respostas de P11, e reversão parcial nas respostas de P13 e P15. Já no delineamento BAB, P10 apresentou reversão total, e P12, P14, P16, reversão parcial. Em comum, semelhantemente ao Experimento 1, o critério que permitiu correlacionar os CSSs de linha de base e reversão, no delineamento $\mathrm{ABA}$ ou $\mathrm{BAB}$, foi o efeito de reversão exercido sobre as respostas de checagem.

Por fim, observa-se que não há o aumento da porcentagem das respostas de P9 na fase $\mathrm{B}(\mathrm{ABA})$ em relação à fase $\mathrm{A}$. Contudo, na fase seguinte de reversão $\mathrm{A}$, a frequência apresentada é a mesma da fase B. Esse dado não sugere um controle diferencial dos CSSs 
sobre as respostas de separação nas fases A ou B, ou mesmo, sugere um maior controle da contingência sobre os CSSs ao longo das fases.

\section{DISCUSSÃO GERAL}

Os presentes experimentos com delineamentos de sujeito único podem dar conta de explicar a "etiologia" e a "sintomatologia" de alguns subtipos de transtorno obsessivocompulsivo (TOC), em especial o apresentado pelos chamados de checadores (Franklin, \& Foa, 2008). Dizer de outra forma, eles permitem investigar quais tipos de contingências produzem e mantêm uma alta frequência de respostas de checagem, e ainda por que dadas contingências produzem estes comportamentos característicos, e não outros. Por esse motivo, o estudo serviu à função de apresentar um modelo experimental de TOC com humanos, embasado nas relações empíricas estabelecidas entre alguns estímulos verbais, o contexto da tarefa e o comportamento não verbal de checagem.

O entendimento clássico da regra enquanto SD para o seu seguimento não explica como uma única apresentação logo ao início da fase experimental controla uma maior porcentagem de respostas de checagens emitidas ao longo dos quinze minutos da fase experimental. Uma interpretação do controle pela regra dessa natureza teria que assumir a emissão consistente das regras, de forma encoberta, sempre anteriormente à emissão de uma resposta de checagem (cf., Schlinger, 1990, 1993). Essa concepção conceitual torna-se difícil de ser sustentada nos presentes experimentos. A interpretação de regra como CSS, 
por outro lado, evidencia o controle múltiplo exercido pelo CSS conjuntamente com as circunstâncias relacionadas à tarefa de separação de sementes. Nos Experimentos 1 e 2 os CSSs participam como eventos antecedentes, mas outras variáveis ambientais, como os erros de separação, também entram no controle das respostas de checagem por terem função de estímulo discriminativo.

O aumento da porcentagem das respostas de checagem nas fases B do Experimento 1, por meio da apresentação de CSSs com especificação de consequência aversiva, replica algumas características do estudo de Abreu e Hübner (2011). Naquele experimento dos autores foi observado que ambos os participantes aumentaram a frequência das respostas de checagem na fase C, também de apresentação CSS com especificação de consequência aversiva, sendo que um participante o fez em relação a uma fase B anterior (instrução com autoclítico, mas sem especificação e consequência aversiva) e o outro participante em relação à fase de linha de base. Igualmente semelhante, na fase de reversão, os participantes do estudo de Abreu e Hübner (2011) apresentaram reversão total ou parcial.

O método do Experimento 1, associado aos dados do estudo de delineamento de caso único de Abreu e Hübner (2011), parecem embasar a análise funcional clínica dos comportamentos de checagem enquanto comportamentos de fuga e esquiva (Franklin, \& Foa, 2008). Mais especificamente, no fenômeno clínico as “obsessões” seriam a emissão encoberta de um CSS especificador de consequência aversiva para a resposta inefetiva em produzir mudanças específicas no ambiente. Já as “compulsões” seriam as repostas de checagem em alta frequência, sendo essas controladas, em parte, pelo CSS encoberto. As respostas "compulsivas" têm a função de esquivar ou escapar de algum evento aversivo. No 
caso do Experimento 1 a função seria evitar a perda de dinheiro, e no caso dos checadores em contextos naturais, as funções mais comuns são a esquiva de danos provocados para si, ou para alguma pessoa querida (Franklin, \& Foa, 2008).

O Experimento 2, ao seu turno, teve como objetivo testar se uma instrução com anúncio de consequência apetitiva poderia produzir respostas de checagem. Do ponto de vista respondente, tradicionalmente o TOC foi associado ao controle aversivo. No TOC a teoria dos dois estágios de Mowrer (1960) para a aquisição de respostas de medo e evitação tem sido a teoria mais aceita.

Tentando explicar os determinantes para a aprendizagem e manutenção das respostas de esquiva, Mowrer (1960) descreveu que em um primeiro momento um estímulo neutro é associado a um estímulo aversivo que provoca ansiedade e desconforto. Por pareamento pavloviano, o estímulo neutro passa a ter a mesma função de estímulo com o estímulo anteriormente pareado. No segundo estágio o organismo desenvolveria respostas de fuga ou esquiva do estímulo condicional (CS) com a função de aliviar o sofrimento. Dollard e Miller (1950) estenderam a teoria dos dois estágios de Mowrer para explicar a neurose obsessivo-compulsiva. No modelo dos autores, os pensamentos "obsessivos", e as circunstâncias que os evocam, seriam CSs dos quais o indivíduo tentará escapar ou esquivar com a emissão os comportamentos "compulsivos". Essa concepção do TOC tem sido o mainstream explicativo dentro da tradição clínica comportamental (Franklin, \& Foa, 2008).

No Experimento 2, entretanto, observou-se um o aumento da porcentagem das respostas de checagem nas fases B com a apresentação de CSSs com especificação de consequência 
apetitiva. Os participantes parecem ter aumentado o número das respostas de checagem, com função de produzir melhor desempenho na separação e, com isso, obter o ganho de dinheiro extra anunciado. Os dados expandem as possibilidades de análise funcional das respostas de checagem no fenômeno clínico, sugerindo um questionamento do modelo comportamental de TOC embasado unicamente na hipótese do controle aversivo.

Pela semelhança, os controles por contingencias do Experimento 2 podem explicar alguns fenômenos clínicos. No TOC na vigência de um ambiente com pouca estimulação aversiva, pode ocorrer a transposição nos controles, com o surgimento de uma consequência positivamente reforçadora (Abreu \& Prada, 2004; 2005). Poder-se-ia citar, como exemplo de consequência apetitiva, o reforço social normalmente apresentado pela família de uma mãe com TOC que checa repetidamente a segurança de seu bebê no berço.

Foi o objetivo do método dos presentes experimentos testar se CSSs com especificação de consequência aversiva e apetitiva evocariam maiores porcentagens de respostas de checagem. No Experimento 1 cinco de oito participantes apresentaram maiores porcentagens de checagens sob especificação de consequência aversiva. No Experimento 2 sete de oito participantes apresentaram maiores porcentagens sob especificação de consequência apetitiva. As contingências manipuladas, ainda que verbais, foram suficientes para produzir maiores porcentagens de checagem.

Os Experimentos 1 e 2 não tiveram o objetivo de replicar diretamente ou sistematicamente os estudos cognitivos sobre o comportamento de checagem (Arntz, et al., 2007; Bouchard et al., 1999; Mancini, et al., 2004; Ladouceur et al., 1995; Laudouceur et al., 1997; Lopatka \& Rachman, 1995). Alternativamente, semelhantemente ao estudo de 
Abreu e Hübner (2011), utilizou-se um delineamento de sujeito como seu próprio controle, com fases experimentais de linha de base e reversão. Mais especificamente, utilizou-se um delineamento de grupo com reversão e controle de ordem inter-sujeitos. Dados delineamentos foram preferidos ao delineamento de grupo com controle estatístico pelo fato do estudo estar interessado em investigar o desempenho individual dos participantes, em que pese à importância da identificação e análise da variabilidade produzida como efeito das manipulações experimentais (Cooper et al., 2007). O método experimental de sujeito único, diferente da comparação estatística de grupos, permitiu derivar análises funcionais do fenômeno comportamental envolvido na psicopatologia. Essas análises funcionais, como produto do comportamento verbal dos pesquisadores, poderão no futuro vir a controlar diferencialmente novas intervenções dos terapeutas. 


\section{REFERÊNCIAS}

Abreu, P. R. \& Hübner, M. M. C. (2011). Efeito de instruções sobre respostas de checagem. Psicologia: Teoria e Pesquisa, 27, 81-88.

Abreu, P. R. \& Hübner, M. M. C. (2010). Um modelo experimental do transtorno obsessivo-compulsivo baseado nas relações funcionais entre respostas verbais e não verbais. In M. M. C. Hübner; M. R. Garcia; P. R. Abreu; E. N. P. Cillo; \& P. B. Faleiros (Eds.), Sobre Comportamento e Cognição: Análise Experimental do Comportamento, Cultura, Questões Conceituais e Filosóficas, (pp. 239-246). Santo André: ESETec.

Abreu, P. R. \& Prada, C. G. (2005). Relação entre os condicionamentos operante e respondente no transtorno obsessivo-compulsivo. Revista Estudos de Psicologia, 22, 225-232.

Abreu, P. R. \& Prada, C. G. (2004). Transtorno de ansiedade obsessivo-compulsivo e transtorno da personalidade obsessivo-compulsivo: um "diagnóstico" analíticocomportamental. Revista Brasileira de Terapia Comportamental e Cognitiva, 6, 211 220.

Alessi, G. (1992). Models of aproximate and ultimate causation in psychology. American Psychologist, 47, 1359-1370.

American Psychiatric Association (2003). Diagnostic and statistical manual of mental disorders (4th ed., rev). Washington, DC: Author.

Arntz, A., Voncken, M., \&, Goosen, A. C. A. (2007) Responsibility and obsessivecompulsive disorder: an experimental test. Behavioral Research and Therapy, 45, 425435 .

Baum, W. M. (2005) Understanding behaviorism: behavior, culture, and evolution. Oxford: Blackwell Publishing.

Beck, A. T., \& Epstein, N., Brown, G. \& Steer, R. A. (1988). An inventory for measuring clinical anxiety: psychometric properties. Journal of Consulting and Clinical Psychology, 56, 893-897.

Beck, A. T., Rush. A. J.; Shaw, B. F., \& Emory, G. (1979). Cognitive therapy of depression. New York: Guilford.

Blakely, E., \& Schlinger, H. (1987). Rules: function-altering contingency-specifying stimuli. The Behavior Analyst, 10, 183-187. 
Bouchard, C., \&, Rhéaume, J., \& Ladouceur, R. (1999). Responsibility and perfectionism in OCD: an experimental study. Behavioral Research and Therapy, 37, 239-248.

Borloti, E. (2004). As relações verbais elementares e o processo autoclítico. Revista Brasileira de Terapia Comportamental e Cognitiva, 6, 221-236.

Braam, C., \& Malott, R. W. (1990) "I'll do it when the snow melts." The effects of deadlines and delays on rule-governed behavior. The Analysis of Verbal Behavior, 8, $67-76$

Catania, A. C. (1999). Aprendizagem: comportamento, linguagem e cognição. (Trans. by D. G. Souza) Porto Alegre: Artes Médicas. (Original work published 1998)

Catania, A. C. (2003). Verbal governance, verbal shaping and attention to verbal stimuli. In: K. A. Lattal \& P. N. Chase (Eds.). Behavior Theory and Philosophy (pp. 301-321). New York: Plenum Publishers.

Catania, A. C., Matthews, B. A.; \& Shimoff E. (1982). Instruct versus shaped human verbal behavior: interactions with nonverbal responding. Journal of the Experimental Analysis of Behavior, 38, 233-248.

Cooper, J.O.; Heron, T.E.; Heward, W.L. (2007). Applied behavior analysis (2nd ed.). Prentice Hall.

De Rose, J. C. (1999). O que é um skinneriano? Uma reflexão sobre mestre, discípulos e influência intelectual. Revista Brasileira de Terapia Comportamental e Cognitiva, 1, 67-74.

Dollard, J, \& Miller, N. E. (1950). Personality and psychotherapy: an analysis in terms of learning thinking and culture. New York: McGraw-Hill.

Ferster, C. B. (1973). A functional analysis of depression. American Psychologist, 28, 857870.

Franklin, M. E., \& Foa, E. B. (2008). Obsessive compulsive disorder. In: D. H. Barlow (Ed.). Clinical Handbook of Psychological Disorders, (pp. 164-215). New York: The Guilford Press.

Greer, R. D. (2009). The integration of speaker and listener responses: a theory of verbal development. Psychological Record, 59, 449-488.

Hayes, S. C., \& Hayes, L. J. (1989). The verbal action of the listener as a basis for rulegovernance. In S. C. Hayes (Ed.), Rule-governed behavior: cognition, contingencies and instructional control (pp. 153-190). New York: Plenum. 
Hayes, S. C., Zettle, R. D., \& Rosenfarb, I. (1989). Rule following. In: S. C. Hayes (Ed.), Rule-governed behavior: cognition, contingencies, and instructional control (pp. 191220). New York: Plenum

Hayes, S. C., Barnes-Holmes, D., \& Roche, B. (2001). Relational frame theory: A postskinnerian account of human language and cognition. New York: Kluwer Academic/Plenum Publishers.

Hübner, M. M. C. (2003). Comportamento verbal e não verbal: efeitos de reforçamento de tactos com autoclíticos referentes ao ler sobre o tempo dispendido com leitura. In: H. M. Sadi \& N. M. Castro (Eds.), Ciência e comportamento: conhecer e avançar (pp. 163-173). Santo André: ESETec.

Hübner, M. M., Austin, J., \& Miguel, C. F. (2008). The effects of praising qualifying autoclitics on the frequency of reading. The Analysis of Verbal Behavior, 24, 55-62.

Ladouceur, R.; Rhéaume, J., Freeston, M. H., Aublet, F, Jean, K., Lachance, S., et al. (1995). Experimental manipulations of responsibility: an analogue test for models of obsessive-compulsive disorder. Behavioral Research and Therapy, 8, 937-946.

Ladouceur, R.; Rhéaume, J., \& Aublet, F. (1997) Excessive responsability in obsessional concerns: a fine-grained experimental analysis. Behavioral Research and Therapy, 35, 423-427.

Lloyd, K. E. (2002). Suggestions of correspondence training: suggestions for a revival. The Behavior Analyst, 25, 57-73.

Lopatka, C., \& Rachman, S. (1995) Perceived responsibility and compulsive checking: an experimental analysis. Behavioral Research and Therapy, 33, 673-684.

Malott, R. W. (1988). Rule-governed behavior and behavioral anthropology. The Behavior Analyst, 11, 181-203.

Malott, R. W. (1989). The achievement of evasive goals controlled by rules describing contingencies that are not direct-acting. In S. C. Hayes (Ed.), Rule governed-behavior: cognition, contingencies, and instructional control (pp.269-322). New York: Plenum.

Mancini, F., D’Olimpio, F. \& Cieri, L. (2004) Manipulation of responsibility in nonclinical subjects: does expectation of failure exacerbate obsessive-compulsive behaviors? Behavioral Research and Therapy, 42, 449-457.

Matos, M. A. (2001). Comportamento governado por regras. Revista Brasileira de Terapia Comportamental e Cognitiva, 3, 51-66. 
Michael, J. (1982). Distinguishing between discriminative and motivational functions of stimuli. Journal of Experimental Analysis of Behavior, 37, 149-155.

Michael, J. (1983). Evocative and repertoire-altering effects of an environmental event. The Analysis of Verbal Behavior, 2, 19-21.

Michael, J. (1993). Establishing operations. The Behavior Analyst, 33, 401-410.

Michael, J. (2000). Implications and refinements of establishing operations. Journal of Applied Analysis of Behavior, 33, 401-410.

Mijares-Garcia, M. (2005). Efeito da pré-exposição a dietilpropiona e a cafeína sobre o valor reforçador da dietilpropiona anfetamina. Tese, Instituto de Psicologia, Universidade de São Paulo. São Paulo-SP.

Mistr, K. N., Glenn, S. (1992). Evocative and function-altering effects of contingencyspecifiyng stimuli. The Analysis of Verbal Behavior, 10, 11-21.

Mowrer. O. A. (1960). Learning theory and behavior. New York: Wiley.

Palmer, D. C. (1998). The speaker as listener: The interpretation of structural regularities in verbal behavior. The Analysis of Verbal Behavior, 15, 3-6.

Palmer, D. C. (2007). Verbal behavior: What is the function of structure. European Journal of Behavior Analysis, 8, 161-175.

Perone, M., Galizio, M., \& Baron, A. (1988). The relevance of animal-based principles in the laboratory study of human operant conditioning In: G. Dave, \& C. Cullen (Eds.), Human operant conditioning and behavior modification (pp. 59-85). New York: Wiley \& Sons.

Rachman, S. (2002). A cognitive theory of compulsive checking. Behavioral Research and Therapy, 40, 625-639.

Salkovskis, P. M., Richards, H. C., \& Forrester, E., (1995) The relationship between obsessional problems and intrusive thoughts. Behavioral Research and Therapy, 23, 281-299.

Sanavio, E. (1988) Obsessions and compulsions: the Padua Inventory. Behavioral Research and Therapy, 26, 169-177.

Schlinger, H., \& Blakely, E. (1987). Function-altering effects of contingency-specifying stimuli. The Behavior Analyst, 10, 41-45. 
Schlinger, H., \& Blakely, E. (1994). A descriptive taxonomy of environmental operations and its implications for behavior analysis. The Behavior Analyst, 17, 43-57.

Schlinger, H. (1990). A reply to behavior analysts writing about rules and rule-governed behavior. The Analysis of Verbal Behavior, 8, 77-82.

Schlinger, H (1993). Separating discriminative and function-altering effects of verbal stimuli. The Behavior Analyst, 16, 9-23.

Schlinger, H. D. (2008a). Listening is behaving verbally. The Behavior Analyst, 31, 145161.

Schlinger, H. D. (2008b). Conditioning the behavior of the listener. International Journal of Psychology and Psychotherapy, 8, 309-322.

Sidman, M. (2001) Coerção e suas implicações (Trans. by M. A. Andery \& T. M. Sério). Campinas: Livro Pleno. (Original work published 1989)

Silva, M.T.A., Guerra, L.G.G.C., \& Alves, C. R. R.(2005). Modelos comportamentais em neurociências. Revista Brasileira de Análise do Comportamento, 1, 167-185.

Skinner, B. F. (1968). Science and human behavior. New York/London: Free Press/Collier Macmillan. (Original work published 1953)

Skinner, B. F. (1969). Contingencies of reinforcement: a theoretical analysis. New York: Appleton-Century-Crofts.

Skinner, B. F. (1972). What is psychotic behavior? ( $3^{\text {a }}$ edition) In B. F. Skinner (ed.), Cumulative record: a selection of papers. (pp. 257-275). New York: Meredith Corporation.

Skinner, B. F. (1976). About behaviorism. New York: Vintage Books. (Original work published 1974)

Skinner, B. F. (1988) The fable. The Analysis of Verbal Behavior, 6, 1-2

Skinner, B. F. (1992). Verbal behavior (Definitive edition). Acton, MA: Copley Publishing Group. (Original work published 1957)

Ullmann, L. P. \& Krasner, L. (1975). A Psychological Approach to Abnormal Behavior. (2a Edition) New Jersey: Prentice-Hall.

Vargas, E. A. (1998). Verbal behavior: implications of its mediational and relational characteristics. The Analysis of Verbal Behavior, 15, 149-151. 
Willner, P. (1991). Behavioral models of psychopatology. In P. Willner (Ed.), Behavioural models in psychopatology (pp. 89-125). Cambridge: Cambridge University Press.

Woods, A., Smith, C., Szewczak, M., Dunn, R. W., Cornfeldt, M., \& Corbett, R. (1993) Selective serotonina re-uptake inhibitors decrease schedule-induced polydipsia in rats: a potential model for obsessive compulsive disorder. Psychopharmacology, 112, 195198.

Zamignani, D. R. (2001). Uma tentativa de entendimento do comportamento obsessivocompulsivo: algumas variáveis negligenciadas. In R. C. Wielenska (org.), Sobre comportamento e cognição. Questionando e ampliando a teoria e as intervenções clínicas em outros contextos (pp. 247-256). Santo André: ESETec.

Zamignani, D. R. \& Banaco, R. A. (2005). Um panorama analítico-comportamental sobre os transtornos de ansiedade. Revista Brasileira de Terapia Comportamental e Cognitiva, 7, 77-92. 
APÊNDICES 
APÊNDICE 1

TERMO DE CONSENTIMENTO LIVRE E ESCLARECIDO 


\section{Universidade de São Paulo Hospital Universitário HU}

São Paulo, de 2012.

\section{Carta de Informação aos Participantes de Pesquisa}

Há doze anos, pesquisas em nível de Pós Graduação vêm sendo desenvolvidas sobre linguagem, em particular, estudos sobre o efeito de diferentes tipos de instruções verbais sobre o comportamento não-verbal das pessoas. Dadas pesquisas são feitas buscando proporcionar procedimentos especiais para aumento do entendimento de processos básicos de linguagem na psicologia. Os estudos são conduzidos sob a coordenação e supervisão da Profa. Dra. Maria Martha Costa Hübner. Temos tido a colaboração de pessoas que nos autorizam a conduzir nossos estudos. Elas atendem a dois requisitos pelos quais foram escolhidas para a pesquisa: são adultos e possuem domínio da linguagem.

A presente pesquisa, intitulada "Um modelo experimental do transtorno obsessivocompulsivo baseado nas relações funcionais entre respostas verbais e não verbais", tem como objetivo analisar os fatores básicos que afetam o processo de tomada de decisão em tarefas que envolvem algum grau de responsabilidade pessoal, identificando os fatores e procedimentos relacionados aos comportamentos de checagem. Para isso ela utilizou uma tarefa básica de separação de diferentes tipos de sementes. A coleta de dados desse estudo iniciará em 2012, sendo finalizada no mês de fevereiro do mesmo ano.

Das experiências anteriores, podemos garantir que as pessoas ficam satisfeitas em participar das sessões de pesquisa. Ao final de cada sessão, como ajuda de custos, pagamos uma pequena quantia em dinheiro $(\mathrm{R} \$ 20,00)$. Enfatizamos que não há qualquer risco a saúde dos participantes da pesquisa. Verificamos ainda que, como benefício aprendido, os participantes obtêm um aprimoramento do autoconhecimento em situações de tomada de decisão que envolvem responsabilidade pessoal.

Esclarecemos, também, que por se tratar de uma pesquisa, os dados e resultados são confidenciais e sua identidade não é revelada, quando da divulgação do trabalho.

Caso $\mathrm{V} \mathrm{S}^{\mathrm{a}}$ concorde, solicitamos a gentileza de oficializar essa concordância, preenchendo e assinando o Termo de Consentimento Livre e Esclarecido anexo, e devolvendo-o a seguir ao monitor responsável pela pesquisa.

Colocando-nos a disposição para quaisquer contatos que se fizerem necessários no telefone (Pesquisador Paulo Abreu - 041 92233702), ou no endereço Av. Prof. Mello Moraes, 1721, Cidade Universitária, Instituto de Psicologia, Laboratório de Estudos de Operantes Verbais, Bloco F. Se preferir, poderá também entrar em contato com o CEP-HU, no endereço Av. Prof. Lineu Prestes, 2565, Cidade Universitária, CEP: 05508-000, São Paulo - SP, pelo telefone: 011 3091-9457, fax: 011 3091-9452, ou ainda, pelo e-mail: cep@hu.usp.br. 
Agradecemos,

Maria Martha Costa Hübner

Pesquisadora Responsável, Departamento de Psicologia Experimental do IPUSP

Paulo Roberto Abreu

Pesquisador Participante, Doutorando do Departamento de Psicologia Experimental do IPUSP 


\section{Universidade de São Paulo \\ Comitê de Ética em Pesquisa \\ Termo de Consentimento Livre e Esclarecido}

Pelo presente instrumento, que atende às exigências legais, o(a) senhor(a) , participante de pesquisa, após leitura da Carta de Informação ao Participante de Pesquisa, ciente dos serviços e procedimentos aos quais foi submetido, não restando quaisquer dúvidas a respeito do lido e do explicado, firma seu Consentimento Livre e Esclarecido de concordância em participar da pesquisa proposta.

Fica claro que o participante de pesquisa ou seu representante legal podem, a qualquer momento, retirar seu Consentimento Livre e Esclarecido e deixar de participar do estudo alvo da pesquisa e fica ciente que todo trabalho realizado torna-se informação confidencial, guardada por força do sigilo profissional.

Assinatura do participante da pesquisa e $\mathrm{n}^{\mathbf{0}}$ do $\mathrm{RG}$

Sexo

Endereço

Telefone

Data de nascimento

"Declaro que, após convenientemente esclarecido pelo pesquisador e ter entendido o que me foi explicado, consinto em participar do presente Projeto de Pesquisa."

São Paulo, __ de ___ de 2012 
APÊNDICE 2

APROVAÇÃO DO PROJETO DE PESQUISA E DO TERMO DE CONSENTIMENTO LIVRE E ESCLARECIDO JUNTO AO COMITÊ DE ÉTICA DO HOSPITAL UNIVERSITÁRIO DA USP 


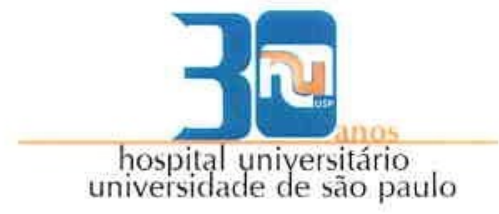

São Paulo, 17 de dezembro de 2011.

$I l^{m o(a)} . S^{r(a)}$.

Profa. Dra. Maria Martha Costa Hübner

Departamento de Psicologia Experimental do Instituto de Psicologia UNIVERSIDADE DE SÃO PAULO

REFERENTE: Projeto de Pesquisa "Um modelo experimental do transtorno obsessivocompulsivo baseado nas relações funcionais entre respostas verbais e não verbais" Pesquisador(a) responsável: Profa. Dra. Maria Martha Costa Hübner - Pesquisador executante: Paulo Roberto Abreu - Registro CEP-HU/USP: 1161/11 - SISNEP CAAE: 0048.0.198.000-11.

Prezado(a) Senhor(a)

O Comitê de Ética em Pesquisa do Hospital Universitário da Universidade de São Paulo, em reunião ordinária realizada no dia 16 de dezembro de 2011, analisou o Projeto de Pesquisa acima citado, considerando-o como APROVADO, bem como o seu Termo de Consentimento Livre e Esclarecido.

Lembramos que cabe ao pesquisador elaborar e apresentar a este Comitê, relatórios anuais (parciais ou final, em função da duração da pesquisa), de acordo com a Resolução n 196/96 do Conselho Nacional de Saúde, inciso IX.2, letra "c".

O primeiro relatório está previsto para 16 de dezembro de 2012.

Atenciosamente,

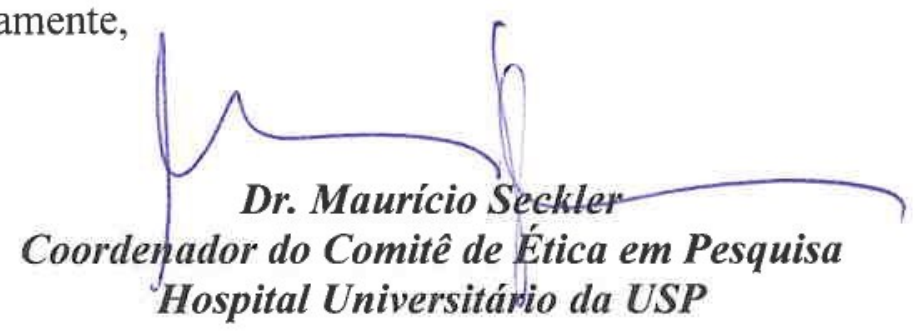

